\title{
Neural Coding of Whisker-Mediated Touch in Primary Somatosensory Cortex Is Altered Following Early Blindness
}

\author{
-Deepa L. Ramamurthy and Leah A. Krubitzer \\ Center for Neuroscience, University of California, Davis, California 95618
}

\begin{abstract}
Sensory systems do not develop and function independently of one another, yet they are typically studied in isolation. Effects of multisensory interactions on the developing neocortex can be revealed by altering the ratios of incoming sensory inputs associated with different modalities. We investigated neural responses in primary somatosensory cortex (S1) of short-tailed opossums (Monodelphis domestica; either sex) after the elimination of visual input through bilateral enucleation very early in development. To assess the influence of tactile experience after vision loss, we also examined naturally occurring patterns of exploratory behavior. In early blind (EB) animals, overall levels of tactile experience were similar to those of sighted controls (SC); locomotor activity was unimpaired and accompanied by whisking. Using extracellular single-unit recording techniques under anesthesia, we found that EB animals exhibited a reduction in the magnitude of neural responses to whisker stimuli in S1, coupled with spatial sharpening of receptive fields, in comparison to SC animals. These alterations manifested as two different effects on sensory processing in S1 of EB animals: the ability of neurons to detect single whisker stimulation was decreased, whereas their ability to discriminate between stimulation of neighboring whiskers was enhanced. The increased selectivity of S1 neurons in EB animals was reflected in improved population decoding performance for whisker stimulus position, particularly along the rostrocaudal axis of the snout, which aligns with the primary axis of natural whisker motion. These findings suggest that a functionally distinct form of somatosensory plasticity occurs when vision is lost early in development.
\end{abstract}

Key words: barrel cortex; compensatory plasticity; crossmodal; somatosensation; vibrissae; vision loss

Significance Statement

After sensory loss, compensatory behavior mediated through the spared senses could be generated entirely through the recruitment of brain areas associated with the deprived sense. Alternatively, functional compensation in spared modalities may be achieved through a combination of plasticity in brain areas corresponding to both spared and deprived sensory modalities. Although activation of neurons in cortex associated with a deprived sense has been described frequently, it is unclear whether this is the only substrate available for compensation or if plasticity within cortical fields corresponding to spared modalities, particularly primary sensory cortices, may also contribute. Here, we demonstrate empirically that early loss of vision alters coding of sensory inputs in primary somatosensory cortex in a manner that supports enhanced tactile discrimination.

\section{Introduction}

The developing nervous system is highly sensitive to the relative levels and patterns of incoming sensory inputs, not only within,

\footnotetext{
Received Jan. 7, 2018; revised May 20, 2018; accepted May 23, 2018

Author contributions: D.L.R. wrote the first draft of the paper; D.L.R. and L.A.K. edited the paper; D.L.R. and L.A.K. designed research; D.L.R. performed research; D.L.R. analyzed data; D.L.R. and L.A.K. wrote the paper.

This work was supported by the National Eye Institute-National Institutes of Health (Grant R01EY022987-03 to L.A.K. and Grant 2T32EY015387-11 to D.L.R.), the National Science Foundation (Graduate Research Fellowship Program Grant DGE-1650042 to D.L.R.), and the James S. McDonnell Foundation (Grant 220020516 to L.A.K.). We thank Daniel Feldman for many helpful discussions; Mary Baldwin, Andrew Halley, and Mackenzie Englund for comments on a draft of this manuscript; Cindy Clayton for animal care; and Cynthia Weller, Tanner Kovacs, Sarah Daley, Heather Dodson, Carly Jones, Mina Sadraei, Linda Oppizzi, and Mackenzie Englund for experimental assistance.

The authors declare no competing financial interests.

Correspondence should be addressed to Leah A. Krubitzer, Center for Neuroscience, University of CaliforniaDavis, 1544 Newton Court, Davis, CA 95618. E-mail: lakrubitzer@ucdavis.edu.

DOI:10.1523/JNEUROSCI.0066-18.2018

Copyright $\odot 2018$ the authors $\quad 0270-6474 / 18 / 386172-18 \$ 15.00 / 0$
}

but also across sensory modalities. Numerous studies in humans (for review, see Bavelier and Neville, 2002; Renier et al., 2014; Ricciardi et al., 2014) and other mammals (Karlen et al., 2009; for review, see Butler and Lomber, 2013) have reported the phenomenon of crossmodal plasticity in which cortical areas associated with a deprived sensory modality become responsive to stimuli associated with spared modalities. These effects are observed, to varying degrees, after different forms of sensory loss including congenital abnormalities (Hunt et al., 2006; Chabot et al., 2007), peripheral lesions (Izraeli et al., 2002; Kahn and Krubitzer, 2002; Meredith et al., 2011), decreased sensory-driven activity (Rauschecker and Korte, 1993; Rauschecker, 1996), or naturally occurring loss of vision during evolution (e.g., blind mole rat; Bronchti et al., 2002; Sadka and Wollberg, 2004). Further, behavioral evidence from congenitally blind or deaf mammals, including hu- 
mans, indicates that, after early sensory loss, animals perform better on tasks mediated by spared sensory systems (Toldi et al., 1994; Rauschecker and Kniepert, 1994; Lomber et al., 2010; for review, see Bavelier and Neville, 2002; Ricciardi et al., 2014).

The majority of these studies have focused on the deprived cortex as the main substrate for functional and behavioral compensation that accompanies early sensory loss. However, an increase in the cortical territory available for processing information in the spared senses via recruitment of the deprived cortex is not necessarily the only mechanism for sensory compensation. Instead, compensation may involve some combination of a takeover of the deprived cortex by spared sensory systems as well as a reorganization of cortical and subcortical structures associated with the spared sensory modalities. However, studies examining the effects of early loss on cortical areas associated with the spared senses are limited, particularly with regard to primary sensory cortices. Rauschecker et al. (1992) reported an expansion of the barrel fields in $\mathrm{S} 1$ in neonatally enucleated mice, as determined by cytochrome oxidase staining. A previous study from our laboratory (Kahn and Krubitzer, 2002) found that neurons at some recording sites in primary somatosensory cortex (S1) and primary auditory cortex (A1) were responsive to both somatosensory and auditory stimuli in animals that were bilaterally enucleated very early in development. Beyond this, the effects of early and chronic unimodal sensory loss on neural processing in the spared senses are not well understood.

The goal of the current study was to test whether there were basic differences in tactile processing in $\mathrm{S} 1$ of animals that experienced early vision loss (early blind, EB) compared with sighted control (SC) animals. We did this by examining extracellular single-unit activity in response to a simple tactile stimulus, the deflection of a single whisker. Short-tailed opossums are ideal for studies of the consequences of early sensory loss on cortical function because their nervous systems are highly immature at birth, allowing for targeted extrauterine manipulations at much earlier developmental stages than most commonly used mammalian models. Both the visual and somatosensory systems are well developed in adult short-tailed opossums; primary visual cortex (V1) is the primary sensory area that occupies the largest fraction of the neocortex, followed by S1 (Huffman et al., 1999; Kahn et al., 2000). Further, short-tailed opossums exhibit specialized tactile behavior in the form of whisking, a rhythmic and stereotypic back-and-forth motion of the facial whiskers during spatial exploration and navigation (Mitchinson et al., 2011; Grant et al., 2013). Thus, in the absence of one dominant sense (vision), one might expect neural and behavioral shifts toward the other dominant sense (touch). Recently, a study from our laboratory demonstrated reorganization of both thalamic and cortical projections to S1 in bilaterally enucleated animals (J. C. Dooley and L.A. Krubitzer, unpublished observations), in addition to the reorganization of projections to visual cortical areas (Karlen et al., 2006). In light of these observations, we were particularly interested in investigating whether plasticity after early blindness has implications for neural coding in S1.

\section{Materials and Methods}

Animals. A total of 44 short-tailed opossums (Monodelphis domestica) of either sex (SC: 11 females, 11 males; EB: 10 females, 12 males) derived from 13 litters (from 11 mothers) were used for data collection across all behavioral and electrophysiological testing conducted in the current study (see Tables 1 and 2 for details regarding subject information). Extracellular electrophysiological recording techniques were used in 19 adult (4-16 months) animals to examine the response properties and
Table 1. Subject information: SC animals

\begin{tabular}{|c|c|c|c|c|c|c|c|c|}
\hline \multirow[b]{2}{*}{ ID\# } & \multirow[b]{2}{*}{ Sex } & \multirow{2}{*}{$\begin{array}{l}\text { Weight at } \\
\text { adulthood } \\
\text { (g) }\end{array}$} & \multirow{2}{*}{$\begin{array}{l}\text { S1 neural } \\
\text { recordings }\end{array}$} & \multicolumn{4}{|c|}{ Behavioral data collected } & \multirow[b]{2}{*}{$\begin{array}{l}\text { Whisking } \\
\text { present? }\end{array}$} \\
\hline & & & & $\begin{array}{l}\text { Occurrence } \\
\text { of whisking }\end{array}$ & $\begin{array}{l}\mathrm{L} / \mathrm{W} \\
\text { overlap }\end{array}$ & & $\begin{array}{l}\text { me cage locomotion/ } \\
\text { e range }\end{array}$ & \\
\hline 1 & $\mathrm{~F}$ & 59 & $\mathrm{~N}$ & $Y$ & $\mathrm{~N}$ & $Y$ & Postwean & $Y$ \\
\hline 2 & $\mathrm{~F}$ & 61 & Y & $Y$ & $\mathrm{~N}$ & $Y$ & Adult & Y \\
\hline 3 & $\mathrm{~F}$ & 61 & Y & $Y$ & $\mathrm{~N}$ & $\mathrm{~N}$ & - & $Y$ \\
\hline 4 & $\mathrm{~F}$ & 64 & $\mathrm{~N}$ & Y & $\mathrm{N}$ & Y & Postwean & Y \\
\hline 5 & $\mathrm{~F}$ & 68 & $\mathrm{~N}$ & Y & $\mathrm{Y}$ & Y & $\begin{array}{l}\text { Prewean, postwean, } \\
\text { adult }\end{array}$ & Y \\
\hline 6 & $\mathrm{~F}$ & 71 & Y & $Y$ & $\mathrm{~N}$ & $\mathrm{~N}$ & - & Y \\
\hline 7 & $\mathrm{~F}$ & 72 & $\mathrm{~N}$ & $Y$ & $Y$ & Y & Postwean & $Y$ \\
\hline 8 & $\mathrm{~F}$ & 72 & $Y$ & $Y$ & $\mathrm{~N}$ & $\mathrm{~N}$ & - & Y \\
\hline 9 & $\mathrm{~F}$ & 74 & $\mathrm{~N}$ & $Y$ & $Y$ & $\mathrm{~N}$ & - & Y \\
\hline 10 & $\mathrm{~F}$ & 78 & $\mathrm{~N}$ & $Y$ & $\mathrm{~N}$ & $Y$ & Prewean & Y \\
\hline 11 & $\mathrm{~F}$ & 85 & $Y$ & $Y$ & $\mathrm{~N}$ & $\mathrm{~N}$ & - & $Y$ \\
\hline 12 & M & 87 & Y & $Y$ & $\mathrm{~N}$ & $\mathrm{~N}$ & - & $Y$ \\
\hline $13^{*}$ & M & 93 & Y & $Y$ & $\mathrm{~N}$ & $\mathrm{~N}$ & - & $Y$ \\
\hline 14 & $M$ & 96 & $\mathrm{~N}$ & Y & $\mathrm{N}$ & $Y$ & Postwean & $Y$ \\
\hline 15 & M & 103 & $\mathrm{~N}$ & Y & $\mathrm{N}$ & Y & Postwean & Y \\
\hline 16 & M & 108 & $\mathrm{~N}$ & Y & $Y$ & Y & Prewean & Y \\
\hline 17 & $M$ & 110 & $\mathrm{~N}$ & Y & $Y$ & $Y$ & Postwean, adult & Y \\
\hline $18^{*}$ & M & 113 & Y & Y & $\mathrm{N}$ & $\mathrm{N}$ & - & Y \\
\hline $19^{*}$ & M & 118 & Y & Y & $\mathrm{N}$ & $\mathrm{N}$ & - & $Y$ \\
\hline 20 & $M$ & 133 & Y & $Y$ & $\mathrm{~N}$ & $N$ & - & $Y$ \\
\hline 21 & $M$ & 98 & $\mathrm{~N}$ & $Y$ & $\mathrm{~N}$ & $N$ & Adult & $Y$ \\
\hline 22 & $M$ & 92 & $\mathrm{~N}$ & Y & $Y$ & $Y$ & Prewean, postwean & $Y$ \\
\hline
\end{tabular}

Shown is a breakdown of sex, weight, age range, and parameters measured for SC animals. Asterisks indicate animals for which a portion of neural recording data used were reported in a previous publication (Ramamurthy and Krubitzer, 2016).

Table 2. Subject information: EB animals

\begin{tabular}{|c|c|c|c|c|c|c|c|c|}
\hline \multirow[b]{2}{*}{ ID\# } & \multirow[b]{2}{*}{ Sex } & \multirow{2}{*}{$\begin{array}{l}\text { Weight at } \\
\text { adulthood } \\
\text { (g) }\end{array}$} & \multirow[b]{2}{*}{$\begin{array}{l}\text { S1 neural } \\
\text { recordings }\end{array}$} & \multicolumn{4}{|c|}{ Behavioral data collected } & \multirow[b]{2}{*}{$\begin{array}{l}\text { Whisking } \\
\text { present? }\end{array}$} \\
\hline & & & & $\begin{array}{l}\text { Occurrence } \\
\text { of whisking }\end{array}$ & $\begin{array}{l}\text { L/W } \\
\text { overlap }\end{array}$ & & $\begin{array}{l}\text { me cage locomotion/ } \\
\text { e range }\end{array}$ & \\
\hline 1 & $\mathrm{~F}$ & 59 & $\mathrm{~N}$ & $Y$ & Y & $Y$ & Prewean & Y \\
\hline 2 & $\mathrm{~F}$ & 62 & Y & $Y$ & $\mathrm{~N}$ & $N$ & - & Y \\
\hline 3 & $\mathrm{~F}$ & 63 & $\mathrm{~N}$ & $Y$ & $Y$ & $Y$ & Postwean, adult & $Y$ \\
\hline 4 & $\mathrm{~F}$ & 65 & $\mathrm{~N}$ & $Y$ & $\mathrm{~N}$ & $Y$ & Postwean & $Y$ \\
\hline 5 & $\mathrm{~F}$ & 70 & Y & $Y$ & $\mathrm{~N}$ & $\mathrm{~N}$ & - & Y \\
\hline 6 & $\mathrm{~F}$ & 71 & $Y$ & $Y$ & $\mathrm{~N}$ & Y & Adult & Y \\
\hline 7 & $\mathrm{~F}$ & 76 & $\mathrm{~N}$ & $Y$ & $Y$ & $Y$ & Postwean & $Y$ \\
\hline 8 & $\mathrm{~F}$ & 78 & $\mathrm{~N}$ & $Y$ & $\mathrm{~N}$ & $Y$ & Prewean, postwean & $Y$ \\
\hline 9 & $\mathrm{~F}$ & 79 & $\mathrm{~N}$ & $Y$ & $\mathrm{~N}$ & Y & Prewean & Y \\
\hline 10 & $\mathrm{~F}$ & 87 & Y & $Y$ & $\mathrm{~N}$ & $\mathrm{~N}$ & - & Y \\
\hline 11 & $M$ & 61 & Y & $Y$ & $\mathrm{~N}$ & $\mathrm{~N}$ & 一 & Y \\
\hline 12 & M & 79 & Y & $Y$ & $\mathrm{~N}$ & Y & Prewean, postwean & Y \\
\hline 13 & M & 86 & Y & $Y$ & $\mathrm{~N}$ & $\mathrm{~N}$ & - & Y \\
\hline 14 & M & 88 & $\mathrm{~N}$ & $Y$ & Y & $Y$ & Adult & Y \\
\hline 15 & M & 93 & Y & $Y$ & $\mathrm{~N}$ & $\mathrm{~N}$ & - & Y \\
\hline 16 & M & 165 & $Y$ & $Y$ & $\mathrm{~N}$ & $\mathrm{~N}$ & - & Y \\
\hline 17 & M & 89 & $\mathrm{~N}$ & $Y$ & $\mathrm{~N}$ & $Y$ & Prewean & Y \\
\hline 18 & M & 107 & $\mathrm{~N}$ & $Y$ & $Y$ & $\mathrm{~N}$ & - & Y \\
\hline 19 & M & 110 & $\mathrm{~N}$ & Y & $Y$ & $Y$ & Prewean, postwean & $Y$ \\
\hline 20 & M & 113 & $\mathrm{~N}$ & $Y$ & $\mathrm{~N}$ & $Y$ & Prewean & $Y$ \\
\hline 21 & M & 116 & $\mathrm{~N}$ & $Y$ & $Y$ & $Y$ & Postwean, adult & Y \\
\hline 22 & M & 124 & $\mathrm{~N}$ & $Y$ & $Y$ & $Y$ & Prewean, postwean & $Y$ \\
\hline
\end{tabular}

Shown is a breakdown of sex, weight, age range, and parameters measured for $E B$ animals.

receptive field characteristics for neurons in S1. Nine animals ( 4 females, 5 males) were bilaterally enucleated on postnatal day 4 (P4) and are referred to as 'early blind' (EB), and 10 animals (5 females, 5 males) served as 'sighted controls' (SC). Portions of electrophysiological data acquired from three SC animals were reported in a previous publication (Ramamurthy and Krubitzer, 2016). All animals were housed in standard laboratory cages and maintained on a 14/10 h light/dark cycle. Food and water were available ad libitum in the home cage. To determine whether enucleation affected opossum behavior, we examined locomotor activity 
and whisking behavior in SC and EB animals (see below). Protocols were approved by the Institutional Animal Care and Use Committee of the University of California-Davis and experiments were performed according to the criteria outlined in the National Institutes of Health's Guide for the Care and Use of Laboratory Animals.

Bilateral enucleation. Bilateral enucleations were performed on shorttailed opossum pups at P4. Because the pups are fused to the mother's nipples until $\sim$ P14, the procedure was performed after lightly anesthetizing the mother with Alfaxan $(20 \mathrm{mg} / \mathrm{kg}$, IM). Maintenance doses (10$50 \%$ ) were administered as needed to ensure that the mother remained immobile. Pups were anesthetized by hypothermia through contact with a rubber pouch filled with ice and each eye was removed manually under microscopic guidance. After enucleation, the skin around the eye was repositioned to cover the eye socket and sealed with surgical glue. This entire procedure for both eyes lasted for 3-4 min per animal. Approximately half of each litter was bilaterally enucleated to generate EB group animals and the remaining half served as the SC group. Respiration rate and body temperature of the mother and heartbeat, coloration, and mobility of the pups were monitored throughout the enucleation procedure. Following enucleations, the pups were allowed to rewarm and once the pups and mother were fully recovered, they were returned to the home cage.

Behavioral data collection and analysis. Animals from three age ranges were used for behavioral data collection: preweaning juvenile (P36P56), postweaning juvenile (P56-P76), and adult (4-16 months) animals. Qualitative assessments of whisking behavior were made for all animals included in the study. In some cases, high-speed video of whisking was captured using a Casio EX-F1 digital video camera $(512 \times 384$ pixels at 300 frames/s) or an Apple iPhone 6 s camera $(1280 \times 720$ pixels at $240 \mathrm{frames} / \mathrm{s}$ ). Movies of whisking were uniformly adjusted for brightness, contrast, and color balance using VLC media player version 2.2.6 (VideoLAN). Presence or absence of whisking was scored by two independent observers on a binary scale as absent or present using a modification of previously used criteria (Landers and Philip Zeigler, 2006) where "absent" refers to no whisking or small, aperiodic whisker movements and "present" refers to low frequency/low amplitude whisking or normal whisking. Whiskers were also tracked in high-speed video clips (mean frames per clip: $\mathrm{SC}=248 \pm 34.3$ frames; $\mathrm{EB}=330 \pm 66.4$ frames) using the Manual Whisker Annotator (Hewitt et al., 2016) to obtain measurements of whisking frequency (number of whisk cycles per second). To assess the overlap between whisking behavior and locomotor activity, individual animals were monitored for 10 epochs of $30 \mathrm{~s}$ each in their home cage, followed by 10 epochs of $30 \mathrm{~s}$ each after transfer to a novel cage containing unfamiliar toys (Bio-Serv). Overlap between whisking $(\mathrm{W}+=1, \mathrm{~W}-=0)$ and locomotion $(\mathrm{L}+=1, \mathrm{~L}-=0)$ bouts was quantified as the L/W overlap index as follows:

$$
\text { For } n \text { tested epochs, L/W overlap index }=\frac{\sum_{i=1}^{n} \min (\mathrm{Li}, \mathrm{Wi})}{\sum_{i=1}^{n} \max (\mathrm{Li}, \mathrm{Wi})}
$$

An L/W overlap index value of 1.0 indicates complete overlap between locomotion bouts and whisking bouts and a value of 0.0 indicates no overlap between locomotion bouts and whisking bouts.

To assess locomotor activity in EB and SC animals, video recordings were obtained of juvenile and adult animals in their home cages over $24 \mathrm{~h}$ periods using an infrared-enabled camcorder (SEREE HDV-501, 30 frames/s). All home cage behavior data were analyzed offline by three independent observers such that, for multiple video segments, the same time windows were analyzed by at least two observers. Interrater reliability for scored videos was quantified using Cohen's $\kappa$ coefficient (see "Experimental design and statistical analysis" section below). Video coding of home cage behavior was performed offline using BORIS (Behavioral Observation Research Interactive) software. Locomotion was scored using a binary scale of active states (locomotion bouts) and inactive states (resting bouts). A switch between an active and inactive state was only considered to have occurred if a bout lasted for at least $60 \mathrm{~s}$. For juvenile animals, mean activity levels for the EB pups versus SC pups in each litter was obtained because each litter was housed together during the preweaning and postweaning stages and individual pup identity could not be tracked.

Surgical procedures. Once enucleated and control animals reached adulthood, we used extracellular recording techniques to examine neural response properties in S1. Animals were anesthetized with urethane (1.25 $\mathrm{g} / \mathrm{kg}, 30 \%$ in saline, IP) at the beginning of the experiment, with supplemental doses $(0.125-0.313 \mathrm{~g} / \mathrm{kg}, 30 \%$ in saline, IP) provided as needed. Respiration and body temperature were monitored throughout the experiment. Dexamethasone $(0.4-2.0 \mathrm{mg} / \mathrm{kg}$, IM) was given at the beginning of the surgery to prevent intracranial swelling. Lidocaine $(2 \%$ solution) was injected subcutaneously at the midline of the scalp and around the ears and the animal was placed in a stereotaxic frame. An incision was made at the midline of the scalp, the temporal muscle was retracted, and a craniotomy was made over parietal cortex. The dura was retracted and the surface of the brain was covered with silicone fluid to prevent desiccation. A digital image was obtained of the exposed neocortex so that electrode penetration sites could be related to vascular patterns. A small screw was inserted into the skull over the opposite hemisphere and the head of the animal was stabilized by cementing the screw to a head post with dental acrylic.

Electrophysiological recordings. Single-unit extracellular recordings were made from layer IV (400-500 $\mu \mathrm{m}$ depth below the pial surface) using insulated tungsten microelectrodes (FHC; $1-5 \mathrm{M} \Omega$ at $1 \mathrm{kHz}$ ). Electrodes were lowered using a hydraulic microdrive (David Kopf Instruments). The location of each recording site was marked relative to the vascular pattern on a digital image of the cortical surface. Receptive fields were initially rapidly determined using a handheld probe. If receptive fields were found to be located on the mystacial whisker pad (centered within the grid of 16 large whiskers), computer-controlled whisker deflections were used to measure tuning of single neurons quantitatively (see below). Single and multiunit activity was recorded in response to whisker deflections and all recorded data were amplified (gain: 10,000×; A-M Systems Model 1800 Microelectrode AC Amplifier), streamed as continuous voltage traces sampled at $28 \mathrm{kHz}$ (Power1401; Cambridge Electronic Design), and saved for analysis. Neural activity was monitored using a digital oscilloscope and an audio amplifier during the experiment. Raw traces were band-pass filtered $(300-3000 \mathrm{~Hz})$ and spike sorting was performed offline to verify isolation of single units. In addition, local field potentials (LFPs) were recorded in over half of the animals (6SC, 6 EB) in each experimental group that were used for recording single-unit data. In each case, LFP data were acquired intermittently throughout the recording session (total measurements: $n=27$ in SC animals, $n=30$ in EB animals). LFP recordings were amplified at $1000 \times$ gain and bandpass filtered $(0.1-100 \mathrm{~Hz})$

At the end of the recording session, electrolytic microlesions (10 $\mu \mathrm{A}$ for $10 \mathrm{~s}$ ) were made and fluorescent probes were inserted at specific locations relative to blood vessel landmarks so that electrophysiological recording sites could be related directly to histologically identified cortical field boundaries and specific laminae of the neocortex.

Whisker stimulation. Receptive fields and response properties were quantified using methods similar to those described previously by us (Ramamurthy and Krubitzer, 2016). Whiskers were deflected using calibrated computer-controlled piezoelectric actuators. Each individual whisker was trimmed to a length of $\sim 15 \mathrm{~mm}$ and inserted into a short, lightweight plastic capillary tube glued to a piezoelectric bimorph element (Q220-AY-203YB; Piezo Systems) fixed on a moveable, jointed arm. During stimulus presentation, the whisker pad was observed under a surgical microscope to ensure that the skin or whiskers adjacent to the deflected whisker were not being extraneously stimulated. Stimuli consisted of $2^{\circ}$ ramp-hold-return deflections ( $4 \mathrm{~ms} \mathrm{ramp}, 100 \mathrm{~ms}$ hold, $4 \mathrm{~ms}$ return; applied $5 \mathrm{~mm}$ from the base of the whisker, causing a $1.4 \mathrm{~mm}$ forward excursion of the whisker) with an interstimulus interval of 1-2 s. At each recording site, 50-100 trials per stimulus per whisker were collected. To determine receptive fields of neurons, 16 neighboring whiskers on the mystacial pad were individually deflected in a pseudorandom order (in blocks of 3-50 trials), at every recording site. 
Histology. After electrophysiological recording experiments, animals were injected with a lethal overdose of sodium pentobarbital (Beuthanasia; $250 \mathrm{mg} / \mathrm{kg} \mathrm{IP}$ ) and transcardially perfused with $0.9 \%$ saline, followed by $2-4 \%$ paraformaldehyde in phosphate buffer, and then $2-4 \%$ paraformaldehyde in $10 \%$ phosphate-buffered sucrose. After perfusion, the brain was extracted. In some cases, the brain was left intact and sectioned coronally ( $3 \mathrm{~EB}, 3 \mathrm{SC}$ ). In other cases, the cortex was peeled from the brainstem and thalamus, flattened between glass sides and sectioned tangential to the cortical surface (6 EB, $7 \mathrm{SC}$ ).

For tangentially sectioned tissue, the cortical hemispheres were postfixed (1-2 h) in $4 \%$ paraformaldehyde in $10 \%$ phosphate-buffered sucrose and then left to soak overnight in $30 \%$ phosphate-buffered sucrose. The flattened cortical hemispheres were sectioned at $30 \mu \mathrm{m}$ on a freezing microtome. Tangential sections of the neocortex were processed for myelin (Gallyas, 1979; Dooley et al., 2013). Electrode sites, blood vessels, and fiduciary probes were transposed from high-resolution images obtained during surgery onto a reconstruction of the cortical surface with cortical field boundaries drawn in Adobe Illustrator CS5. Architectonic boundaries of cortical fields were determined using an entire series of sections stained for myelin. Cortical field boundaries were determined for individual sections and then collapsed onto a single reconstruction and matched to electrode penetration sites by aligning blood vessels and probes.

For coronally sectioned tissue, the whole brain was cut at $40 \mu \mathrm{m}$, processed for Nissl substance, and used for reconstructing the position of recording sites relative to laminar boundaries. Digital images of cortical sections were obtained using either a Nikon Multiphot system or an Optronics MicroFire digital microscope camera. When necessary, whole images were adjusted for contrast and brightness using Adobe Photoshop CS5.

Neural data analysis. All raw data files of electrophysiological recordings were processed blind to the experimental group. To compare brain state and anesthetic depth (Friedberg et al., 1999; Castro-Alamancos and Oldford, 2002; Hirata and Castro-Alamancos, 2011; Pagliardini et al., 2012; Self et al., 2014) between the two experimental groups, LFP recordings of baseline activity were analyzed; the power spectrum of the signal for each LFP recording was computed using fast Fourier transform (FFT) analysis. Single units were isolated during the experiment using templatematching procedures in Spike2 (Cambridge Electronic Design; RRID: SCR_000903) and unit isolation was verified offline in Spike2 using principal component analysis. Only neuronal clusters with a stable waveform and firing rate over the course of a session were included in the analysis. Included units were required to have $<0.5 \%$ refractory period violations (interspike interval $<1.5 \mathrm{~ms}$ ).

Spike times of well-isolated single units were exported to MATLAB (The MathWorks; RRID:SCR_001622) for analysis using custom scripts. Spike trains were aligned to stimulus onset, and peristimulus time histograms (PSTHs) were constructed using a $1 \mathrm{~ms}$ bin width. Neural responses were integrated over a $100 \mathrm{~ms}$ time window following stimulus onset for all spike count analyses. Analyses were performed only for onset responses. Spontaneous firing rates were measured during an equivalent time window during the prestimulus recording period. A neuron was considered to exhibit a significant evoked response if the response magnitude exceeded the prestimulus spike count by $>2$ SDs. Only neurons that displayed a significant onset response to at least 1 whisker were included in all subsequent analyses. The best whisker (BW) for a neuron was defined as the whisker that evoked the highest response magnitude. The whiskers at the 8 positions immediately adjacent to the BW are referred to as first-order $\left(1^{\circ}\right)$ surround whiskers (SW) and the whiskers immediately beyond those are referred to as second-order $\left(2^{\circ}\right)$ SWs.

A tuning curve was generated for each neuron after ranking whisker stimuli in order of the magnitude of the spike count following stimulus onset (rank 1-16; BW = rank 1). Tuning curves were then averaged across neurons to generate a mean tuning curve, or normalized to the peak (the BW-evoked response) and then averaged across neurons to generate the mean normalized tuning curve for each group. Relative magnitudes of neural responses to SWs were obtained by dividing absolute SW-evoked response magnitudes by the BW-evoked response.
Sparseness $(S)$ was used to quantify neuronal selectivity, as per Vinje and Gallant (2000) as follows:

$$
S=\left\{1-\left[\frac{\left(\frac{\sum r_{i}}{n}\right)^{2}}{\sum\left(\frac{r_{i^{2}}}{n}\right)}\right]\right\} /\left[1-\left(\frac{1}{n}\right)\right]
$$

where $r_{\mathrm{i}}$ is the spike count in response to the $i$ th whisker stimulus (averaged across trials) and $n$ is the number of whiskers tested. Values of $S$ near $0 \%$ indicate a "dense" code and values near $100 \%$ indicate a "sparse" code.

Mean 2D somatotopic receptive fields were examined by aligning the response magnitude matrix (in which each element corresponds to the magnitude of the neural response to the deflection of a single whisker) associated with individual neurons such that the BW was at the center of the receptive field in each case. SW-evoked response magnitudes were normalized by dividing by the BW-evoked response magnitude. Matrices corresponding to individual neurons were then averaged across the population to generate the mean $2 \mathrm{D}$ receptive field. Contour plots were generated by plotting 50\%, 70\%, and 90\% isolines (response levels relative to the BW) after smoothing the response magnitude matrix by linear interpolation. Smoothed contour lines were used only for $2 \mathrm{D}$ visualization of mean receptive fields. All calculations and statistical comparisons related to mean tuning curves were made using raw, unsmoothed values.

The tuning width index for each neuron was calculated as the mean response to stimulation of the first-order SWs divided by the response to stimulation of the BW, with values closer to 1 indicating broader receptive fields. The shape index was calculated as the difference between the row tuning width index (mean neural response to SWs in BW row $\div$ BW-evoked response) and the arc tuning width index (mean response to SWs in $\mathrm{BW}$ arc $\div$ BW-evoked response) divided by their sum. In cases where the sum of the row and arc tuning width indices was zero, the shape index was assigned to be zero. Shape index values range from -1 to 1 , with positive values indicating broader tuning along the row compared with the arc and negative values indicating broader tuning along the arc compared with the row.

We examined the ability of single neurons in S1 to detect whisker stimulation and to discriminate between stimulation of different whiskers using signal detection theory (Green and Swets, 1966; Britten et al., 1992). For each neuron, the total number of spikes that occurred in a 100 ms time window after a single whisker deflection was measured (response magnitude, $R_{\text {mag }}$ ). Using these single trial spike counts measured on 50 trials (per whisker) a spike count distribution was generated for each whisker that was deflected. The separability of the spike count distributions associated with different whiskers was then measured using receiver operating characteristic (ROC) analysis. An ROC curve was generated for each pair of spike count distributions being compared, and the area under the ROC curve (AUROC) was used as a measure of detectability or discriminability performance in each case. An AUROC value of 0.5 indicates performance at chance and an AUROC value of 1.0 indicates perfect performance. For discriminability analysis, the spike count distribution associated with BW deflection for a neuron was compared with spike count distributions associated with deflection of SWs. On average, three to four whiskers typically elicit a significant response in any given neuron in S1 of short-tailed opossums (Ramamurthy and Krubitzer, 2016). Therefore, we examined the ability of the neuron to discriminate between the BW and the three most dominant SWs (SW1, SW2, SW3) that elicited the strongest responses in any given neuron. For each neuron, a separate ROC curve was generated for each comparison made (BW vs SW1, BW vs SW2, BW vs SW3), AUROC was measured for each curve, and the mean of the three AUROC values was used as the discrimination index. For detectability analysis, the spike count distribution for a given neuron associated with whisker (BW/SW1/SW2/SW3) deflection was compared with the spontaneous spike count distribution for the same neuron, and the mean AUROC value was used as the detection index for that neuron.

We also examined the performance of neurons in discriminating between multiple whiskers. For each neuron, spike count distributions 
evoked by each of the four most dominant whiskers were nonparametrically modeled using kernel smoothing density estimation. After modeling spike count distributions by kernel density estimation, a Bayesian classifier with cross-validation was used to determine the performance of an ideal observer in discriminating between the four most dominant whisker stimuli (BW, SW1, SW2, SW3). A uniform prior was assumed (equal probability of different whisker stimuli). Overall discrimination performance was calculated as the percentage of correct classifications.

Decoding accuracy of whisker row (A, B, C, D) or arc identity $(0,1,2$, 3 ) based on the population of $S 1$ neurons was determined using a minimum distance classifier (Foffani and Moxon, 2004). The decoding model assumed independence in the activity of different neurons. Since neurons were recorded sequentially, a pseudopopulation was generated in each iteration of the decoding analysis by randomly selecting responses of $n$ recorded neurons from trials corresponding to a given whisker identity ( $n=50$ in each iteration, so population size was matched for SC and EB groups). Thus, each vector consisted of $n$ elements, where each element was the spike count $0-100 \mathrm{~ms}$ after stimulus onset for a given neuron in a given iteration. A leave-one-out cross-validation procedure was used. In the training stage, templates were defined by calculating average number of spikes (0-100 ms) over all training-set trials corresponding to a given whisker, resulting in four templates (corresponding to either rows A-D or arcs $0-3$ ). In the testing stage, a single trial of the pseudopopulation response was classified to the row or arc for which the Euclidean distance between the single trial and the template was the least, compared with distances corresponding to the other templates. Euclidean distance corresponding to a given template was calculated as the sum of the squared differences between each element in the single trial and the template. The decoding analysis was repeated for 200 iterations and average performance and distributions of performance across iterations is reported.

Experimental design and statistical analysis. The current work uses a between-groups study design (i.e., neural response properties of the EB group were compared with those of the SC group) for all comparisons. Statistical analyses were performed in MATLAB version 8.1.0 (The MathWorks; RRID:SCR_001622) and R version 3.2.0 (R Development Core Team, 2015; RRID:SCR_001905). Summary data are given as mean \pm SEM unless otherwise indicated, or as median and interquartile range (IQR), reported as median (IQR). The normality of data was assessed by examining $\mathrm{q}-\mathrm{q}$ plots and by using the Shapiro-Wilk test. If distributions deviated from normal, a nonparametric test such as the Wilcoxon rank-sum test or a permutation test was selected; if no significant deviations were found, two-sample $t$ tests were used. For videos of home cage behavior scored by two independent observers, interrater reliability was quantified using Cohen's kappa coefficient $(\kappa)$, a statistical measure of the level of agreement in scoring performed by independent observers (Landis and Koch 1977, Hallgren, 2012). We used this measure because it corrects for the level of agreement in scoring that may be expected purely by chance as follows:

$$
\kappa=\frac{P_{o}-P_{e}}{1-P_{e}}
$$

where $P_{\mathrm{o}}$ is the observed percentage agreement and $P_{\mathrm{e}}$ is the percentage agreement expected by chance. $\kappa=0$ indicates no agreement in scoring between observers and $\kappa=1$ indicates perfect agreement. For our data, mean $\kappa$ across epochs of home cage behavior scored by two independent observers was $0.861 \pm 0.0261$, indicating a very high level of interrater reliability (Landis and Koch, 1977).

Cohen's U3 was used to assess effect size of between-group differences in population response profiles to whisker stimuli in EB and SC groups and was calculated in MATLAB using the Measures of Effect Size (MES) Toolbox (Hentschke and Stüttgen, 2011; RRID:SCR_014703). Cohen's $U_{3}$ indicates the proportion of data points in one group that are lower in value than the median value for the other group (Hentschke and Stüttgen, 2011). Therefore, an effect size value $>0.5$ in any given time bin indicates that the majority of EB neurons have firing rates lower than the median firing rate for SC neurons in that time bin. Cohen's $d$ was reported as the measure of effect size when comparing group means (small: \pm 0.2 , medium: \pm 0.5 , large: \pm 0.8 ; MES Toolbox; Hentschke and Stüttgen, 2011).

Fisher's exact test was used to compare proportions for categorical variables. Kolmogorov-Smirnov test was used to compare cumulative distributions. Two-way ANOVAs were used to compare EB and SC tuning curves and $\mathrm{EB}$ and $\mathrm{SC}$ behavioral data across different age ranges. ANCOVA was used to compare the slopes of regression lines associated with detection and discrimination indices. A nonparametric multivariate ANOVA (MANOVA) was used to check for influences of sex and individual differences on all measures.

For all statistical tests, differences were considered to be significant when $p<0.05$. Statistical tests used and exact $p$-values for each figure are reported in the Results section.

\section{Results}

In the current study, we investigated the effects of early loss of vision on the coding of whisker-mediated touch in S1. Major milestones in the development of the visual and whisker systems in short-tailed opossums, and the timing of our experimental manipulations and measurements relative to these events are summarized in Figure 1. P0 in short-tailed opossums is equivalent to embryonic ages in commonly used rodent models-E11 in the mouse and E12 in the rat (Molnár and Blakemore, 1995; Molnár et al., 1998). Bilateral enucleations were performed at P4, before retinal afferents and thalamocortical axons have reached their respective targets (Taylor and Guillery, 1994; Molnár et al., 1998). Thus, both spontaneous activity in the retina and visually evoked activity were completely and unequivocally eliminated. We examined patterns of locomotion and associated whisking behavior across $22 \mathrm{SC}$ and $22 \mathrm{~EB}$ animals. Electrophysiological recording experiments were performed in $10 \mathrm{SC}$ animals and 9 EB animals. Across animals, 60/86 recorded units in the SC group and 64/89 recorded units in the EB group exhibited significant responses to whisker stimuli. For all parameters examined (see Materials and Methods), no statistically significant differences were found between sexes or among animals, so all data were combined for analysis. For a breakdown of age range, sex, weight, experimental groups, and parameters measured, see Tables 1 and 2.

\section{Levels of active tactile behavior do not differ between SC and EB opossums}

Any differences observed between SC and EB animals in the neural coding of whisker-mediated touch could potentially be linked to differences in tactile behavior, and therefore, differences in the levels of tactile experience between the two groups. It was critical to rule out the possibility that any neural changes that we measured in EB animals were related to a lack of whisker-mediated experience that could conceivably occur if there were deficits in overall locomotor activity in EB animals, suggesting an inability to compensate for the loss of vision. Further, beyond ruling out deficits in tactile experience, understanding whether levels of tactile experience in EB animals are equivalent to or higher than in SC animals could enable us to make inferences about the mechanisms underlying any compensatory changes observed in the neural representation of touch. For example, if levels of tactile experience are higher in EB animals compared with SC animals, then changes in S1 neural responses may be a consequence of increased reliance on the sense of touch. Alternately, if levels of tactile experience are comparable between EB and SC animals, then the absence of vision itself may be driving compensatory changes in the cortical representation of touch (see Discussion).

Both SC and EB animals engaged in whisking behavior (Fig. $2 A-E)$. Thus, active touch sensation mediated by the whiskers in opossums does not require visual guidance. Distributions of 
A
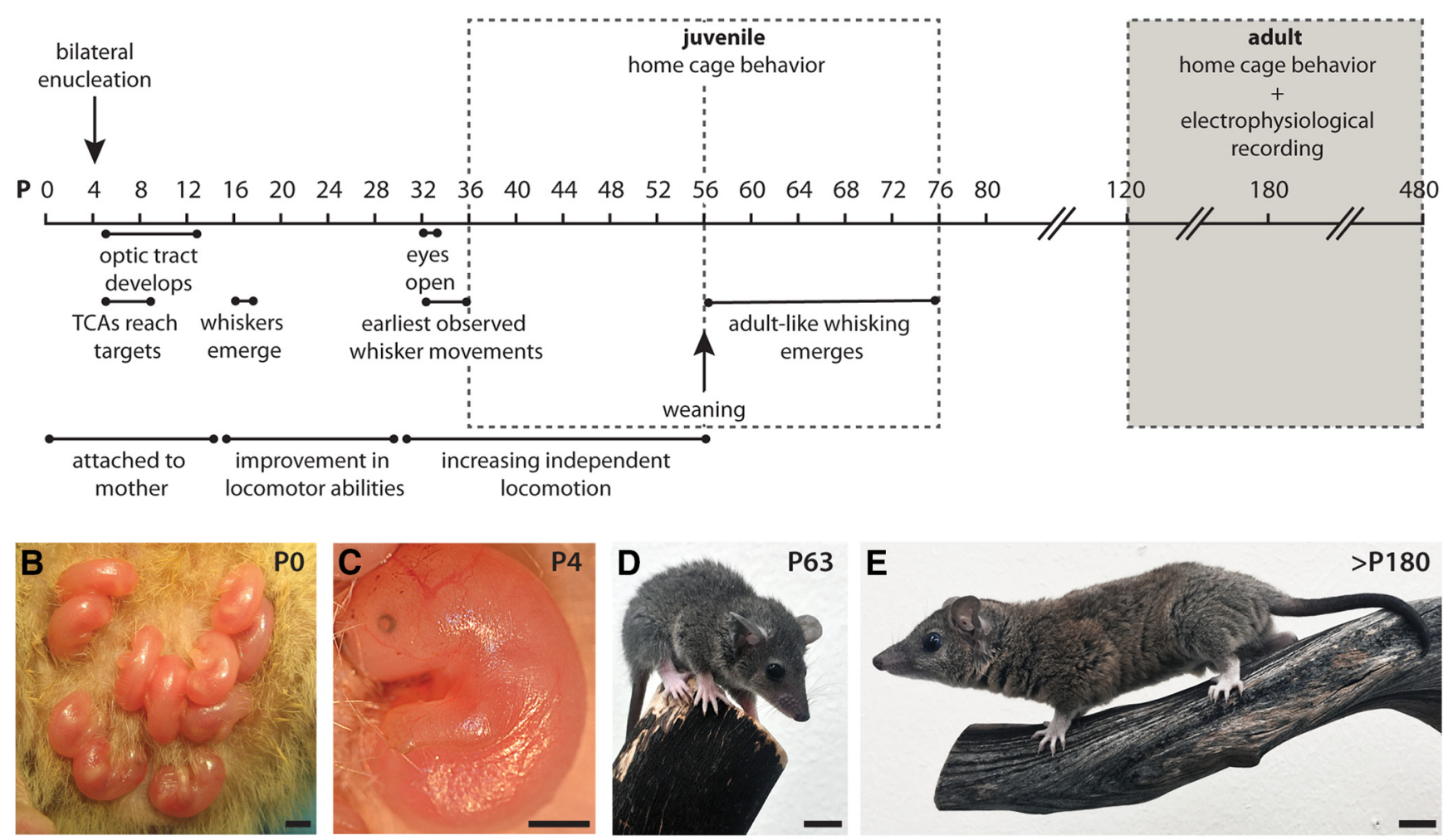

Figure 1. Development in short-tailed opossums and experimental timeline. $A$, Timing of experimental manipulations and data collection relative to developmental milestones in short-tailed opossums. Home cage behavior (dashed box) was examined in juvenile and adult animals. Electrophysiological recording experiments (shaded box) were performed in adult animals. $\boldsymbol{B}, \mathrm{PO}$ litter fused to the nipples on the ventral side of a mother opossum. C, Pup at the age of bilateral enucleation (P4). D, Juvenile animal after weaning (P63). E, Adult animal (>P180). Scale bars: B, C, 2 mm; D, E, 1 cm. [Figure is based on data from Taylor and Guillery, 1994; Molnár et al., 1998; previous work from our laboratory (D. Paulus, S.J. Karlen, L.A. Krubitzer, and C. Clayton, unpublished observations and the current study)]. See Table 3 for a complete list of abbreviations.

\section{Table 3. List of abbreviations used}

\begin{tabular}{ll}
\hline A1 & Primary auditory cortex \\
AUROC & Area under the receiver operating characteristic curve \\
BW & Best whisker \\
CT & Caudal temporal area \\
EB & Early blind \\
FM & Frontal myelinated area \\
IM & Intramuscular \\
IP & Intraperitoneal \\
L(+/-) & Locomotion (present/absent) \\
LFP & Local field potential \\
PSTH & Peristimulus time histogram \\
RF & Receptive field \\
$R_{\text {mag }}$ & Response magnitude \\
S1 & Primary somatosensory cortex \\
S2 & Secondary somatosensory cortex \\
SC & Sighted control \\
Spk & Spikes \\
SW & Surround whisker \\
TCA & Thalamocortical afferents \\
V1 & Primary visual cortex \\
V1-R & Primary visual cortex (reorganized) \\
W(+/-) & Whisking (present/absent) \\
\hline
\end{tabular}

whisking frequency were not significantly different between EB and SC animals across bouts of whisking during free exploration (Fig. $2 A, B$; SC: $n=25$ bouts, EB: $n=17$ bouts; mean: SC $=$ $7.91 \pm 0.328 \mathrm{~Hz}, \mathrm{~EB}=7.74 \pm 0.495 \mathrm{~Hz} ; p=0.762, \mathrm{~d}=0.090$, permutation test). SC and EB animals were initially observed in their home cage and then subsequently in a novel cage, in order to capture bouts of rest as well as locomotion during the monitoring period. Whisking was observed in the home cage and the novel cage conditions for both groups of animals (Fig. 2C). Transfer to the novel cage reliably led to bouts of active exploration through whisking, locomotion, or both (Fig. 2C). We quantified the relationship between locomotion and whisking as the L/W overlap index for each animal tested (see Materials and Methods). Whisking and locomotion were strongly coupled in both SC and EB animals (Fig. $2 D$; mean $\mathrm{L} / \mathrm{W}$ overlap index: $\mathrm{SC}=0.717 \pm 0.107, \mathrm{~EB}=$ $0.762 \pm 0.066 ; p=0.711$, unpaired $t$ test). Whisking occurred in all locomotion bouts recorded during the monitoring period (Fig. $2 E$ ) and in a smaller percentage of resting bouts (SC: $34.3 \%$, EB: $27.6 \% ; p=0.402$, Fisher's exact test). SC and EB groups did not significantly differ in the fractions of locomotion $(\mathrm{L}+)$ and resting $(\mathrm{L}-)$ bouts that contained whisking $(\mathrm{W}+)$. The majority of all whisking bouts in both $\mathrm{SC}$ and $\mathrm{EB}$ occurred during locomotion (SC: $74.5 \%$, EB: 78.4\%; $p=0.526$, Fisher's exact test). Given these results, locomotor activity could be used as a proxy for levels of tactile experience in SC and EB animals.

We investigated patterns of locomotor activity (Fig. $2 \mathrm{~F}-\mathrm{J}$ ) in the home cage over the $24 \mathrm{~h}$ light/dark cycle for EB animals compared to SC animals at juvenile ages (Fig. 2F, top) and adult ages (Fig. 2F, middle and bottom). Duration of activity bouts (Fig. 2G; mean: $\mathrm{SC}=7.07 \pm 1.29 \mathrm{~min}, \mathrm{~EB}=9.84 \pm 1.84 \mathrm{~min} ; p=0.233$, permutation test) and interval event intervals (Fig. $2 \mathrm{H}$; mean: $\mathrm{SC}=46.3 \pm 6.44 \mathrm{~min}, \mathrm{~EB}=45.6 \pm 4.55 \mathrm{~min} ; p=0.934$, permutation test) did not differ between $\mathrm{SC}$ and $\mathrm{EB}$ animals. A conspicuous difference between $\mathrm{SC}$ and $\mathrm{EB}$ animals was in the timing 
A

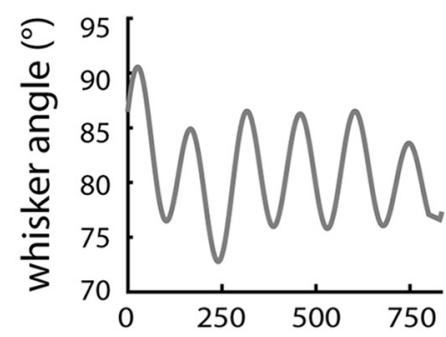

120

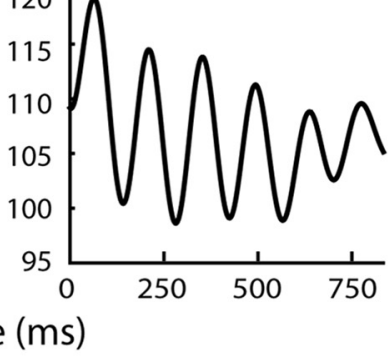

time (ms)
B

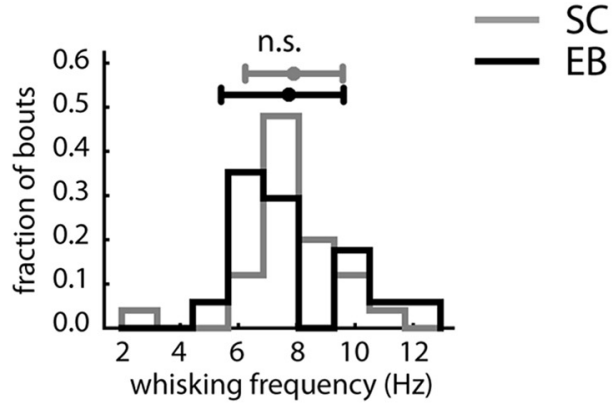

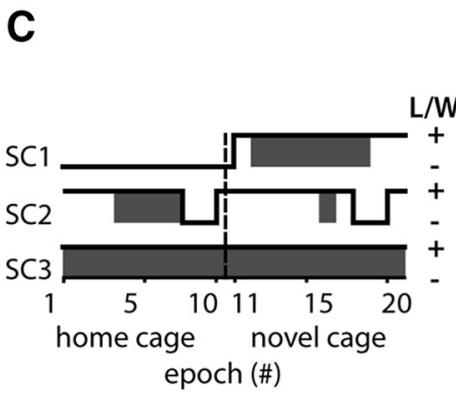

$$
\begin{aligned}
& \text { - locomotion }(\mathrm{L}) \\
& \text { - whisking }(\mathrm{W})
\end{aligned}
$$

E
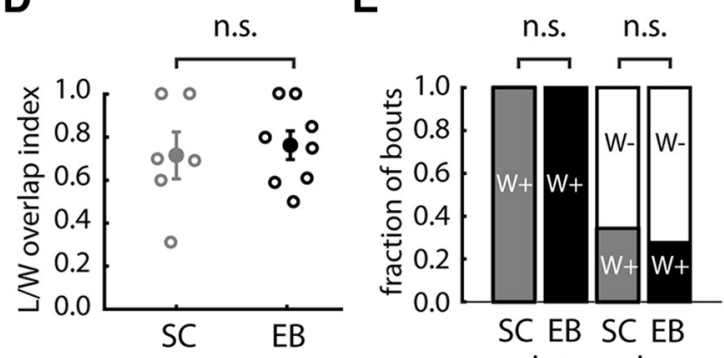

F

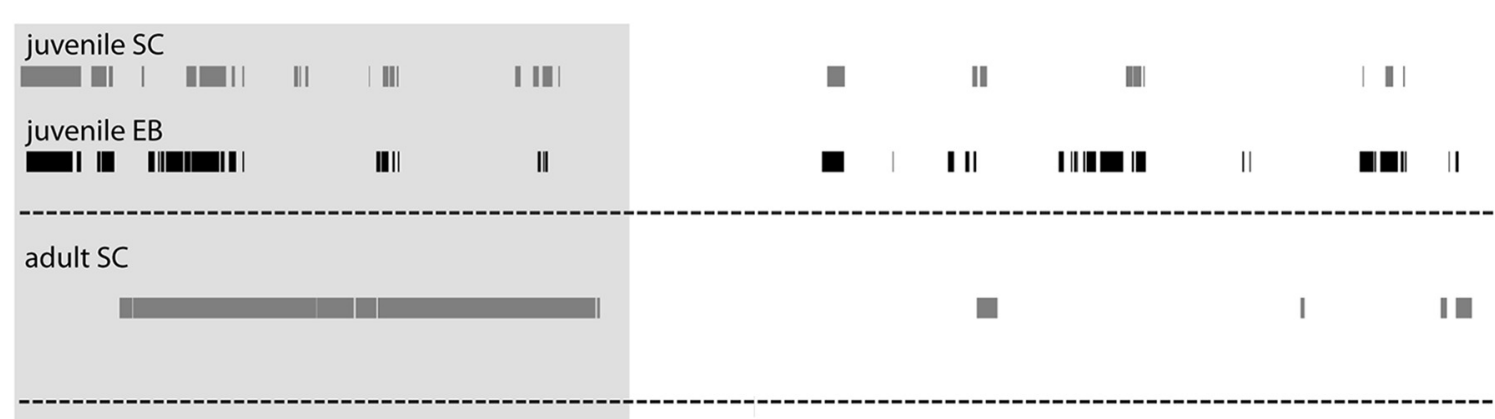

adult EB

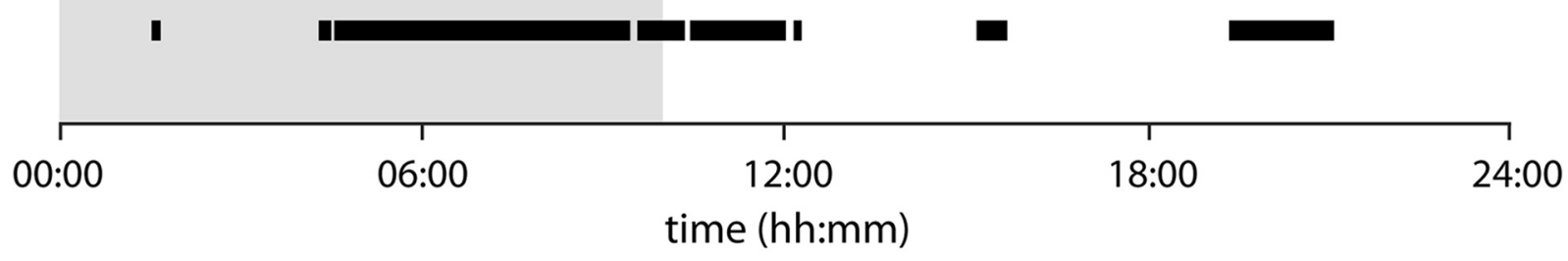

G

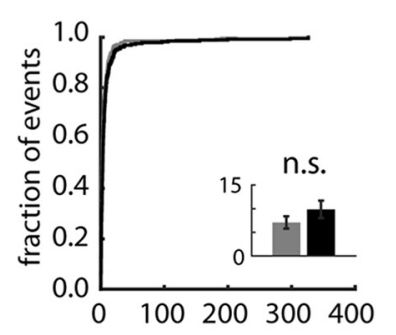

activity bout duration (min)
H

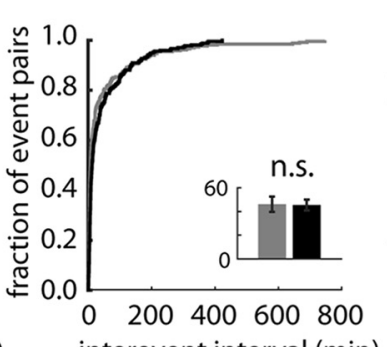

I

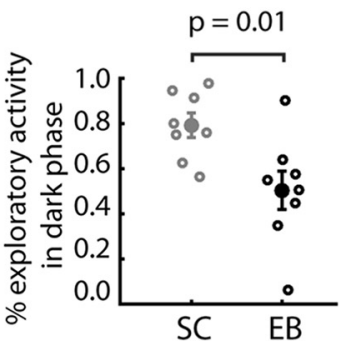

J

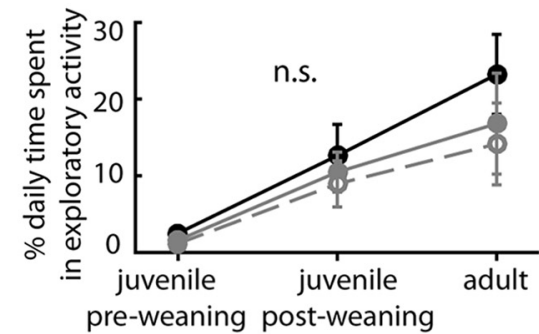

Figure 2. Active exploratory behavior in EB and SC animals. $A$, Example traces of whisker angle in an $S C$ animal (left, gray) and an EB animal (right, black). B, Distributions of whisking frequency across whisking bouts (SC: $n=25, \mathrm{~EB}: n=17$ ) in SC (gray) and EB (black) animals were not significantly different from each other. C, Examples of active exploration in three SC animals (left) and three EB animals (right) in their home cage and in a novel cage. The shaded region indicates the presence of locomotion (L), and the black line indicates the presence of whisking (W). D, Overlap between locomotion and whisking in SC (gray) and EB (black) animals (open circles: data points from individual animals; filled circles: mean \pm SEM). Locomotion and whisking were strongly coupled and the overlap between them was not significantly different between experimental groups. $E$, Presence of whisking as a proportion of the presence of locomotion during exploration. Using a binary criterion, whisking was present in $100 \%$ of locomotion $(\mathrm{L}+)$ bouts, in addition to a smaller proportion of resting $(\mathrm{L}-)$ bouts. Thus, measures of locomotor activity could be used as a proxy for levels of tactile exploration. $F$, Examples of exploratory activity in a $24 \mathrm{~h}$ period ( $14 / 10 \mathrm{hlight} /$ dark cycle; dark hours are indicated by the shaded region) for juvenile (top) and adult ages (middle, bottom) in SC and EB animals. Juvenile SC and EB littermates were cohoused, whereas adult animals were individually housed. Each vertical line indicates an activity bout. $G$, Cumulative distribution of the duration of activity bouts in SC and EB animals; the inset shows mean activity bout durations in SC and EB animals, which were not significantly different between (Figure legend continues.) 
of activity events (Fig. $2 I$; mean: $\mathrm{SC}=79.2 \pm 5.28 \%, \mathrm{~EB}=50.4 \pm$ $8.51 \% ; p=0.012$, unpaired $t$ test). SC animals were primarily active during the dark hours. In contrast, EB animals were, on average, equally active during light and dark hours; they exhibited circadian rhythms that were not entrained to the $24 \mathrm{~h}$ light/ dark cycle. Though the timing of activity events differed between groups, SC and EB animals displayed similar total amounts of exploratory activity in the home cage (Fig. $2 J ; p=0.540,2$-way ANOVA, main effect of experimental group), with an increase in percentages of daily time spent in exploratory activity for both SC and EB groups with increases in age (Fig. $2 J ; p=0.032$, 2-way ANOVA, main effect of age group). Therefore, total levels of tactile experience, as measured using our criteria, did not significantly differ between SC and EB animals. If only tactile experience in the absence of vision is considered, then EB animals (being totally blind) spend 100\% of active bouts (mean: $3.70 \pm$ $0.990 \mathrm{~h} / \mathrm{d}$ ) in nonvisual exploration compared with SC counterparts, which, on average, spend $\sim 80 \%$ of active bouts (mean: $2.30 \pm 0.777 \mathrm{~h} / \mathrm{d}$ ) in nonvisual exploration (Fig. $2 I, J$ ). However, daily hours spent in nonvisual exploratory activity compared across ages were not significantly different between the SC and EB groups (Fig. 2J; $p=0.318$, 2-way ANOVA, main effect of experimental group).

\section{Sampling distributions of $\mathrm{S} 1$ neurons were similar for $\mathrm{EB}$ and $\mathrm{SC}$ animals}

We examined the effects of early blindness on the neural coding of touch by recording neural activity in $S 1$ in response to a simple tactile stimulus, the deflection of a single whisker. Neurons were sampled across the entire representation of the mystacial whiskers, and all analyses were restricted to neurons located in S1 (Fig. $3 A-D)$ at depths corresponding to layer IV, verified post hoc in histologically processed tissue (400-500 $\mu \mathrm{m}$ below the pial surface; Fig. $3 E-H)$. The sampling distribution for both EB and SC animals was strongly skewed toward neurons tuned to ventral row whiskers (Fig. 3I and J, left), potentially reflective of a cortical magnification of ventral whiskers, as discussed previously ( $\mathrm{Ra}-$ mamurthy and Krubitzer, 2016). Whisker arcs were more uniformly represented in the recorded populations (Fig. 3J, right). The fraction of SC and EB populations tuned to whiskers in each row and arc were not significantly different (row: $p=0.962$, arc: $p=0.994$, Fisher's exact test). The distributions of recording depths for all layer IV neurons sampled in S1 of SC and EB animals are shown in Figure $3 \mathrm{~K}$ and were not significantly different between the two groups either for all neurons sampled ( $p=$

$\leftarrow$

(Figure legend continued.) the two groups. $\boldsymbol{H}$, Cumulative distribution of intervals between activity bouts (interevent intervals) in SC and EB animals; the inset shows mean interevent intervals in $\mathrm{SC}$ and $\mathrm{EB}$ animals, which were not significantly different between the two groups. $I$, Percentage of dark hours spent in locomotion in SC and EB animals. For SC animals, the majority of activity occurred during the dark hours, whereas for $\mathrm{EB}$ animals, on average, activity was equally distributed across light and dark hours. J, Time spent in exploratory activity across age groups. For EB animals, mean percentages of daily time spent in exploratory activity are plotted (filled black circles, solid black line) and, for SC animals, both total daily time spent in exploratory activity (filled gray circles, solid gray line) and daily time spent in nonvisual exploratory activity (open gray circles, dashed gray line) are plotted. Although SC and EB animals were, in most cases, active during different times of the day while individually housed (I), there were no significant differences in the total activity levels between $\mathrm{SC}$ and EB animals. Further, because most $\mathrm{SC}$ activity occurred during dark hours, nonvisual exploration constituted the majority of exploratory activity in $\mathrm{SC}$ animals across ages, making it more comparable to tactile exploration in $E B$ animals (in which $100 \%$ of exploratory activity is nonvisual). Therefore, levels of tactile experience did not differ between SC and EB animals. See Table 3 for a complete list of abbreviations.
$0.835, d=0.0306$, permutation test) or for only the neurons that exhibited a significant response to whisker stimuli $(p=0.631$, $\mathrm{d}=0.0923$, permutation test). Examples of units tuned to two different whiskers neighboring each other on the mystacial pad, $\mathrm{C} 0$ and $\mathrm{C} 1$ respectively, are shown for SC (Fig. 4A, B, E,F, I,J, $M, N$; layer IV, recording depths: 409 and $415 \mu \mathrm{m}$ ) and EB (Fig. $4 C, D, G, H, K, L, O, P$; layer IV, recording depths: 411 and 449 $\mu \mathrm{m})$ animals.

\section{Whisker-evoked firing rates, but not spontaneous firing rates, are lower following early blindness}

Whisker stimuli evoked lower magnitude responses in S1 neurons of EB animals compared to those of SC animals (Fig. 5). Population average PSTHs for EB neurons in response to whisker stimuli ranked 1-16 (best to worst) exhibited a relative suppression of firing rates in the case of the BW (rank 1) as well as the majority of SWs (ranks 2-10) except for the lower-ranked whisker stimuli (SW; ranks 11-16), which evoked little to no mean response for either population of neurons (Fig. $5 A$; $p$-values for 2-way ANOVA (main effect of experimental group) by whisker rank: $1: 2.23 \times 10^{-308}, 2: 3.51 \times 10^{-255}, 3: 2.78 \times 10^{-191}, 4$ : $2.21 \times 10^{-118}, 5: 2.76 \times 10^{-74}, 6: 2.47 \times 10^{-77}, 7: 4.56 \times 10^{-35}$, $8: 4.01 \times 10^{-16}, 9: 2.26 \times 10^{-12}, 10: 1.90 \times 10^{-04}, 11: 0.0492,12$ : 0.111, 13: 0.0525, 14: 0.444, 15: 0.611, 16: 0.746). The effect size of relative suppression (Fig. $5 \mathrm{~A}$; Cohen's $\mathrm{U}_{3}$ ) across whisker ranks was greater for population responses associated with stimulation of the most dominant SWs compared to that associated with stimulation of the BW. The relative decrease in firing rates for the EB group of neurons was specific to whisker-evoked responses; spontaneous firing rates were unaltered between the two groups (Fig. $5 B$; significantly responding neurons, median: $\mathrm{SC}=0.813$ (0.213-1.50); $\mathrm{EB}=0.600$ (0.313-1.55), $p=0.789$, Wilcoxon rank-sum test; all recorded neurons, median: $\mathrm{SC}=0.7396$ (0.200-1.35); $\mathrm{EB}=0.600(0.213-1.55), p=0.9628$, Wilcoxon rank-sum test).

Because a few outlier cells (defined as $>1.5$ times the IQR above the third quartile or below the fourth quartile) with higher baseline firing rates were present (Fig. 5B), results of statistical testing for many subsequent analyses are additionally presented after excluding data corresponding to these cells. When considering neurons that exhibited significant whisker-evoked responses $(>2$ SDs above the spontaneous firing rate), the SC population included 6 outlier cells ( 6 of 64 cells) and the EB population included 3 outlier cells ( 3 of 69 cells) that exhibited higher firing rates.

Previous studies have shown similar effects on neural responses caused by differences in brain states (Castro-Alamancos and Oldford, 2002; Hirata and Castro-Alamancos, 2011) and levels of anesthesia (Friedberg et al., 1999; Erchova et al., 2002; Self et al., 2014). To control for this possibility, we performed spectral analysis of LFPs recorded in S1 of SC and EB animals. Both groups showed a clear peak at lower frequencies in the $0-5 \mathrm{~Hz}$ range (Fig. $5 C$; percentage of total FFT power in the $0-5 \mathrm{~Hz}$ band: $\mathrm{SC}=$ $82.0 \pm 2.65 \%, \mathrm{~EB}=84.5 \pm 2.03 \%)$. This is consistent with Guedel stage III-3/III-4 anesthesia (Friedberg et al., 1999). There was no significant difference between the two groups in the total power contained across different frequency ranges (Fig. $5 C ; 5 \mathrm{~Hz}$ frequency bands, $0-60 \mathrm{~Hz} ; p=0.934$, 2-way ANOVA, main effect of experimental group). Further, in all cases in which electrophysiological recordings were made (10 SC, 9 EB), temperature and respiration rate (measures that correlate with fluctuations in brain state; Pagliardini et al., 2012) were consistently monitored throughout the experiment. Mean respiration rate (SC: $48.6 \pm 3.98$ breaths/min, EB: $50.4 \pm 3.59$ breaths $/ \mathrm{min}$ ) 

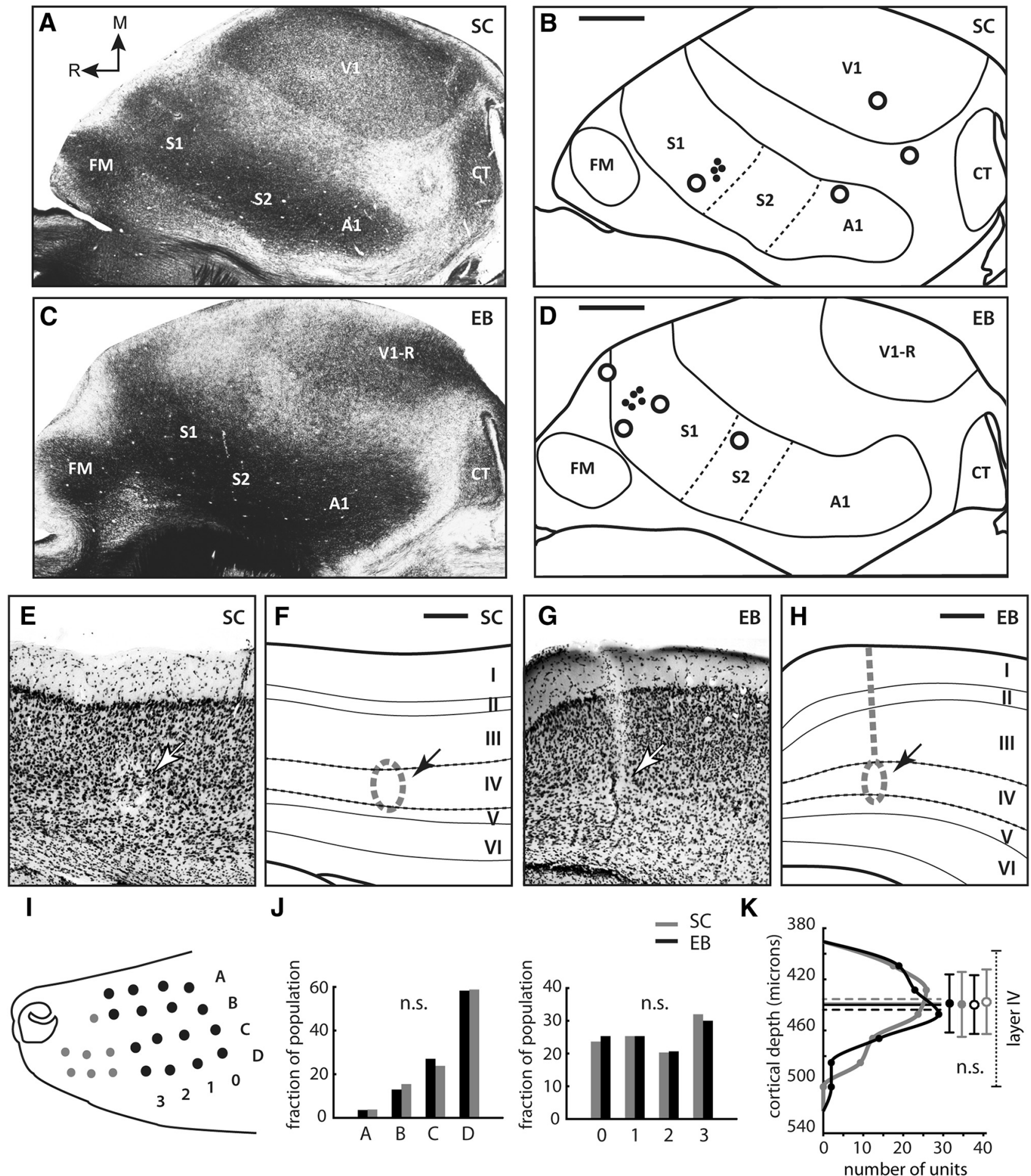

Figure 3. Histological verification of recording sites. $\boldsymbol{A}-\boldsymbol{D}$, Myelin stain of a tangential section of the cortex in an $\mathrm{SC}$ animal $(\boldsymbol{A})$ and an EB animal ( $\boldsymbol{C}$. Reconstructions of myeloarchitectural borders drawn from the entire series of myelin-stained sections in $S C(\boldsymbol{B})$ and $E B(\boldsymbol{D})$ animals. In $\boldsymbol{B}$ and $\boldsymbol{D}$, the location of fluorescent probes is indicated by open circles and the location of recording sites is indicated by black filled circles. Only recording sites at which whisker-evoked responses of neurons were quantified are shown here. In $\boldsymbol{A}-\boldsymbol{D}$, the medial (M) and rostral (R) directions are indicated by arrows. Scale bar, $500 \mu \mathrm{m}$. Coronal sections are stained for Nissl showing $S 1$ in $S C(\boldsymbol{E})$ and $E B(\boldsymbol{G})$ animals and reconstructions of the laminar boundaries of $S 1(\boldsymbol{F}, \boldsymbol{H})$. Electrolytic lesions made at recording sites (indicated by the arrow) are visible in layer IV of the cortex for both SC and EB cases and are shown in the reconstructions (gray dashed circles). In $\boldsymbol{E}-\boldsymbol{H}$, scale bar, $150 \mu \mathrm{m}$. I, Schematic representation of the mystacial whisker pad in short-tailed opossums. Whiskers are identified by their row (A-D) and arc ( 0 - 6$)$ position. For the current study, neurons tuned to the 16 large whiskers (black filled circles) were sampled. Sampling of neurons tuned to whiskers in different positions was matched for SC and EB animals.J, Sampling distribution of neurons that exhibit whisker-evoked responses in SC (gray) and EB (black) animals based on BW row (left) and based on BW arc (right). $K$, Distribution of recording depths of all sampled layer IV neurons in SC (gray) and EB (black) animals. Mean \pm 1 SD (circles) and median (lines) are shown for each distribution for all sampled neurons (filled circles, solid lines) or for all neurons that exhibit a significant response to whisker stimuli (open circles, dashed lines). See Table 3 for a complete list of abbreviations. 


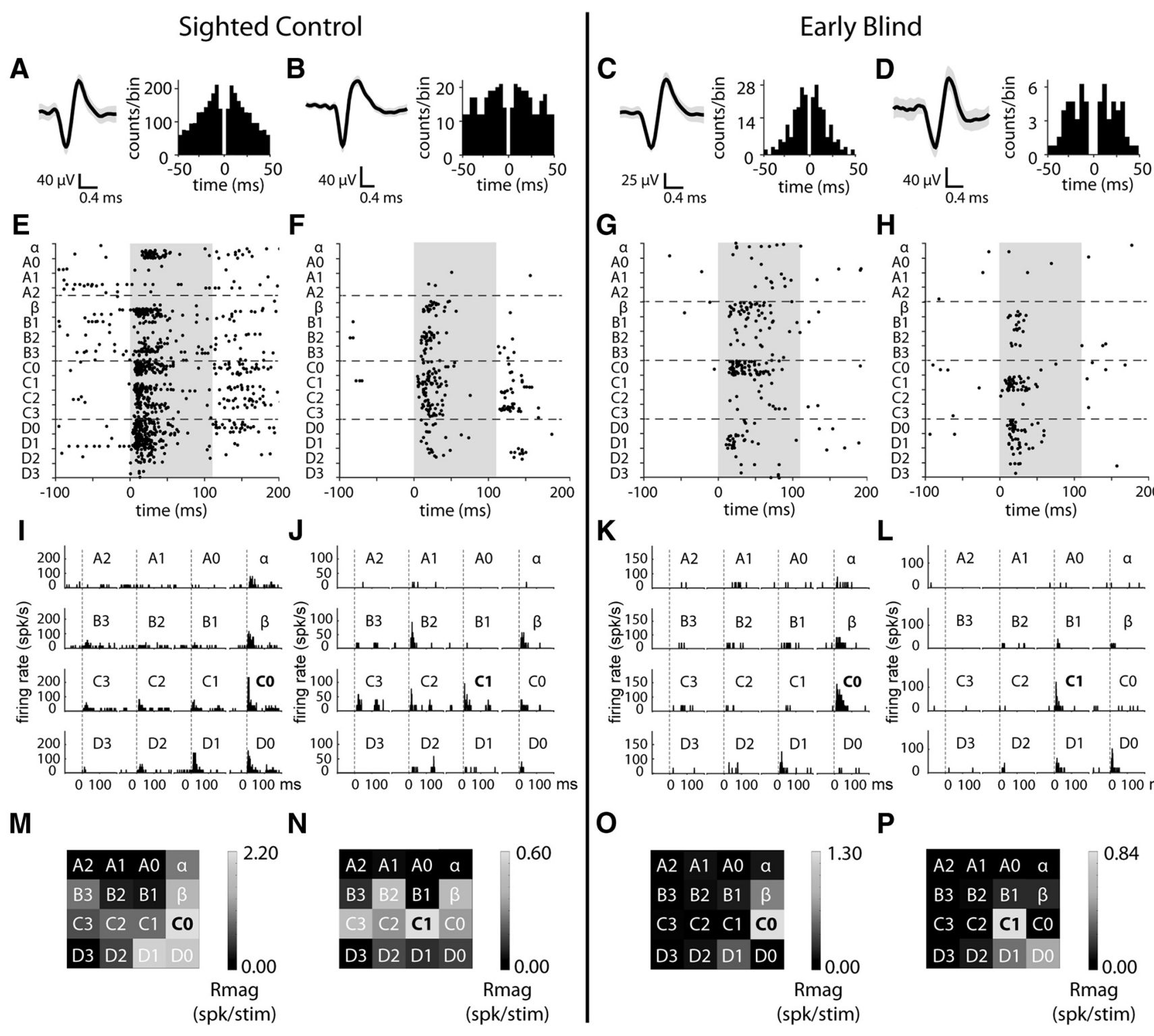

Figure 4. Examples of neural responses recorded in $\mathrm{S1}$ of $S \mathrm{C}$ and $\mathrm{EB}$ animals. Each vertical column of panels corresponds to a single unit recorded in $\mathrm{S1}$ of $S \mathrm{C}$ animals (columns 1-2) or EB animals (columns 3-4). $\boldsymbol{A}-\boldsymbol{D}$, Average spike waveform (on left) showing example SC $(\boldsymbol{A}, \boldsymbol{B})$ and $\mathrm{EB}(\boldsymbol{C}, \boldsymbol{D})$ neurons. The shaded region represents the SD of the mean. Autocorrelograms (on right) for these same neurons show the absence of refractory period violations. $\boldsymbol{E}-\boldsymbol{H}$, Spike raster plots for the example neurons in response to the stimulation of 16 individual mystacial whiskers. The shaded region denotes the duration of the stimulus. $I-L$, Peristimulus time histograms for each of the four example neurons in response to the deflection of the different mystacial whiskers. The dashed lines indicate stimulus onset at $0 \mathrm{~ms} . \boldsymbol{M}-\boldsymbol{P}$, Magnitude of the neuronal response ( $R_{\mathrm{mag}}$, integrated spike count, $\left.0-100 \mathrm{~ms}\right)$ to each whisker. The BW is $\mathrm{C} 0$ in $\boldsymbol{M}$ and $\boldsymbol{O}$ and $\mathrm{C} 1$ in $\boldsymbol{N}$ and $\boldsymbol{P}$, indicated in black font. The grayscale visualizes $R_{\text {mag }}$ relative to the $B W$ response, with lighter shades indicating stronger responses. All conventions are as in previous figures.

and temperature (SC: $91.2 \pm 0.158{ }^{\circ} \mathrm{F}, \mathrm{EB}: 91.1 \pm 0.167{ }^{\circ} \mathrm{F}$ ) measured during neural recordings were not significantly different across all animals between the two groups. Therefore, the differences in whisker-evoked responses between the two groups could not be attributed to differences in brain states or anesthetic levels between the two groups.

\section{Neurons in S1 are more selective to whisker stimuli following} early blindness

Receptive fields, measured as the number of whiskers that evoked a significant response for each single unit, were smaller in EB animals than in SC animals, as indicated by the clear leftward shift in the corresponding cumulative distribution plots (Fig. $5 D ; p=$ $3.47 \times 10^{-05}$, outliers excluded: $p=3.41 \times 10^{-05}$, KolmogorovSmirnov test; $p=1.04 \times 10^{-05}$, outliers excluded: $p=1.64 \times$
$10^{-05}$, Wilcoxon rank-sum test). Given that neural responses to whisker stimuli are suppressed in EB animals compared to SC animals (Fig. 5A), smaller receptive field sizes in EB animals could be due to an overall reduction in response strength or could reflect an increase in selectivity.

We quantified stimulus selectivity of S1 neurons in SC and EB animals by computing sparseness (see Materials and Methods). In EB animals, coding sparseness was substantially increased (Fig. $5 E ; p=8.75 \times 10^{-05}$, outliers excluded: $p=1.19 \times 10^{-04}$, Kolmogorov-Smirnov test), indicating greater selectivity of these neurons for whisker stimuli. A tuning curve was generated for each neuron by plotting the raw spike count values corresponding to each whisker stimulus, arranged by rank. Tuning curves were then averaged across neurons to generate a mean tuning curve for each group. As expected from the population average 
A
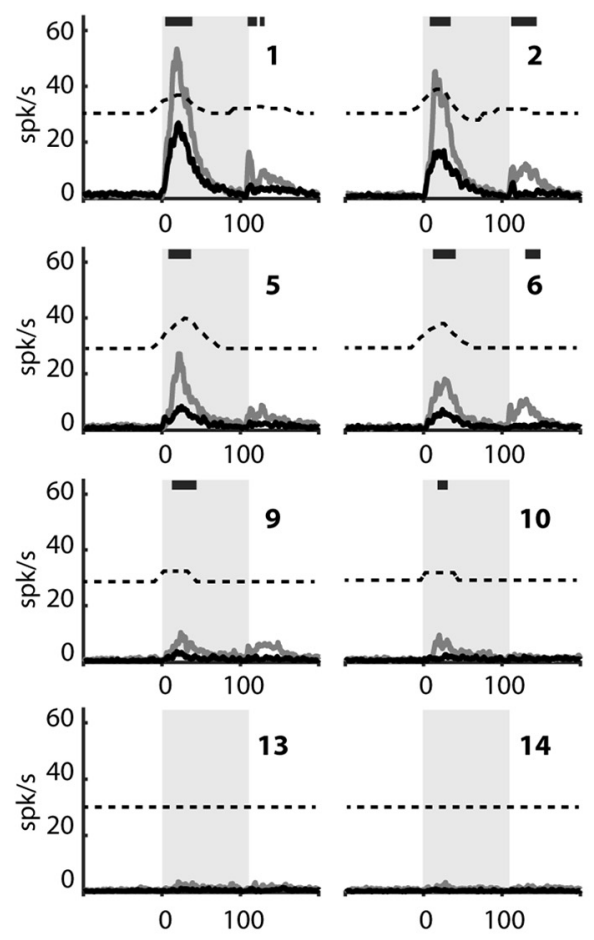

D

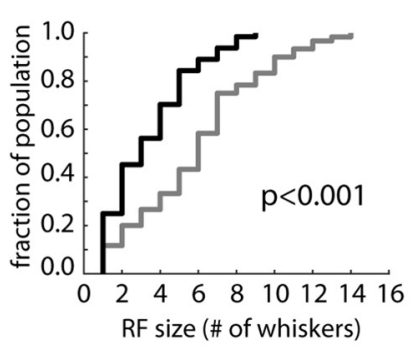

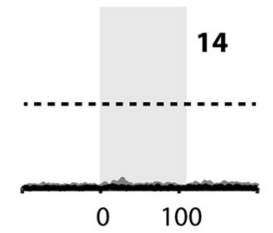

E

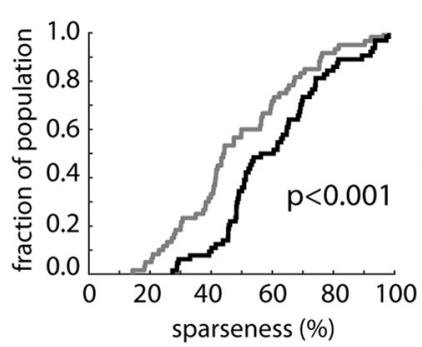

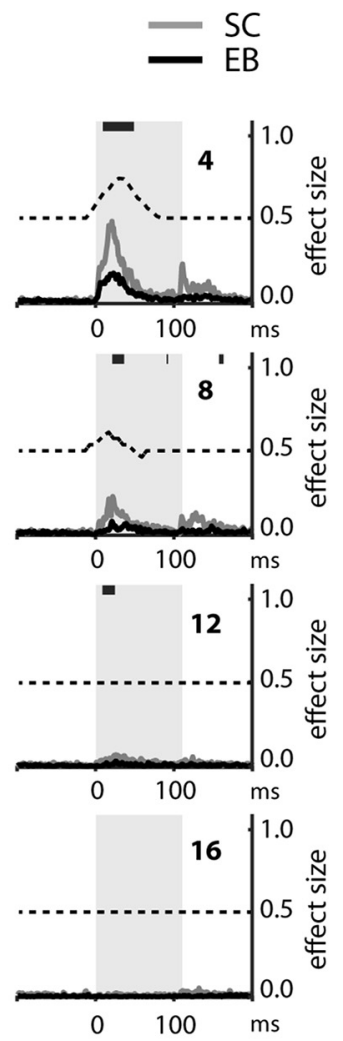

B

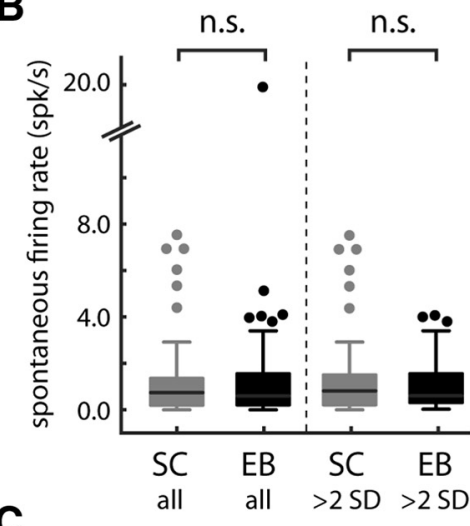

C

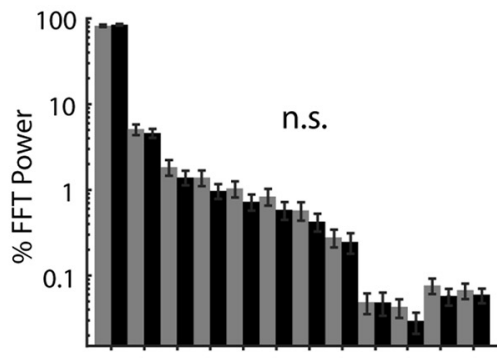

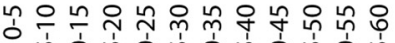

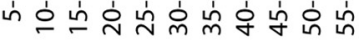
frequency range $(\mathrm{Hz})$
$\mathbf{F}$

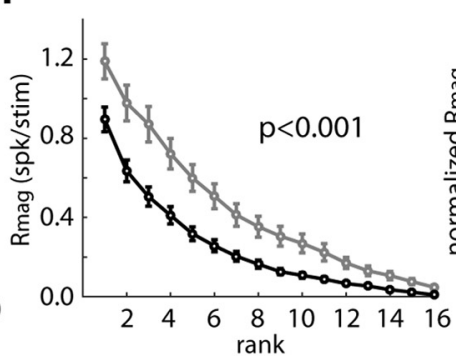

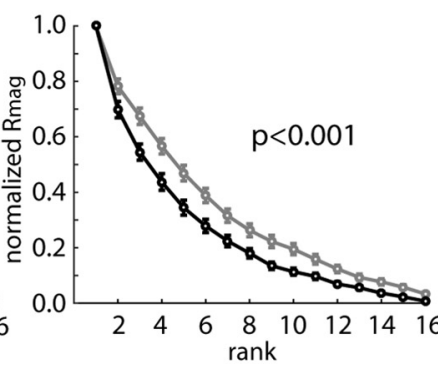

Figure 5. Response characteristics of S1 neurons in EB and SC animals. Whiskers were ranked 1-16 in the order of the magnitude of the response evoked, with 1 being the whisker that evoked the highest magnitude response (BW) and 16 being the whisker that evoked the lowest magnitude response for a given neuron. $A$, Population average PSTHs in response to the deflection of single whiskers in SC (gray) and EB (black) animals. The dashed line indicates effect size (Cohen's $U_{3}$, see Materials and Methods) of the difference between SC and EB firing rate as a function of peristimulus time. Stimulus period is $0-100 \mathrm{~ms}$ in all cases (light-gray-shaded region). Dark gray horizontal bars within the shaded region indicate bins with nonoverlapping confidence intervals (95\%). $\boldsymbol{B}$, Distribution of spontaneous firing rates. Spontaneous firing rates were low in both EB and SC and animals and not significantly different between the two groups either for all recorded cells or for cells that exhibited a significant whisker-evoked response ( $>2$ SD). C, Percentage of total LFP power contained in different frequency bands for SC (gray bars) and EB (black bars) animals. Both groups show a dominance of low frequencies $(0-5 \mathrm{~Hz})$, indicating similar brain states under anesthesia. Error bars indicate mean \pm SEM. $D$, Cumulative distribution of receptive field sizes of single neurons measured as the number of whiskers that evoke a significant response above spontaneous activity. S1 neurons in EB animals exhibited smaller receptive fields than those in $\mathrm{SC}$ animals. $\boldsymbol{E}$, Cumulative distribution of sparseness (see Materials and Methods for calculation) of single neurons in S1. EB neurons show a shift toward higher values of sparseness compared with SC neurons, indicating greater stimulus selectivity for neurons in S1 of EB animals compared with SC animals. $F$, Mean tuning curve of S1 neurons based on raw firing rates (left) in EB and SC animals. EB mean tuning curve is suppressed relative to SC tuning curve for all whisker ranks, reflecting the decrease in magnitude of responses evoked by BW as well as $S W$ deflection. Mean tuning curve of $\$ 1$ neurons after normalization to the magnitude of the BW response is sharper for the EB group compared with the SC group (right). Conventions are as in previous figures.

PSTHs (Fig. 5A), the mean tuning curve for the EB group was suppressed overall, relative to the mean tuning curve for the SC group (Fig. $5 F$, right; $p=2.48 \times 10^{-31}$, outliers excluded: $p=$ $3.19 \times 10^{-20}, 2$-way ANOVA, main effect of experimental group). When individual tuning curves were normalized to their respective peaks (BW-evoked response) and then averaged across the population, mean normalized tuning curves for the EB group were considerably more narrowly tuned than for the SC group (Fig. $5 F$, left; $p=1.07 \times 10^{-25}$, outliers excluded: $p=6.74 \times$ $10^{-20}, 2$-way ANOVA, main effect of experimental group); nonuniform suppression of responses to whisker stimuli across the receptive field added to tuning selectivity beyond a general reduc- tion in response strength. Taken together, these results suggest that spatial resolution for whisker-mediated touch in S1 is enhanced after early blindness.

\section{Stimulus detectability in S1 is degraded following early} blindness, but stimulus discriminability is enhanced We performed ROC analysis to quantify stimulus detectability and discriminability for single units in S1 in EB and SC animals. For each unit, detectability was assessed by comparing whiskerevoked spike count distributions with spontaneous spike count distributions; discriminability was assessed by comparing spike count distributions evoked by the stimulation of different whis- 
kers (Fig. 6A-D). On average, for the four most dominant whiskers in the receptive field (BW, SW1, SW2, and SW3), AUROC values were significantly lower for EB versus SC animals in the case of whisker stimulus detection (Fig. $6 E ; p=1.32 \times 10^{-08}$, outliers excluded: $p=1.44 \times 10^{-07}, 2$-way ANOVA, main effect of experimental group). In contrast, mean AUROC values were significantly higher for EB versus SC animals in the case of discrimination of the BW from the three most dominant SWs (SW1, SW2, and SW3; Fig. $6 E ; p=5.26 \times 10^{-04}$, outliers excluded: $p=$ $1.21 \times 10^{-04}, 2$-way ANOVA, main effect of experimental group). We examined the relationship between detectability and discriminability for single units in S1. The slope of the best-fitting line through mean AUROC values for EB animals was steeper than that for SC animals (Fig. $6 F ; p=2.05 \times 10^{-05}$, ANCOVA, difference in slopes). Therefore, for a given level of stimulus detectability, discriminability was relatively enhanced for S1 neurons in EB animals compared with SC animals.

We further investigated whether there were any differences between EB and SC animals in the ability of the neurons to discriminate between multiple whisker stimuli (Wang et al., 2010; Ollerenshaw et al., 2014) using ideal observer analysis (Fig. 6G,H; see Materials and Methods). Spike count histograms corresponding to different whiskers exhibit varying degrees of overlap (Fig. $6 A-D)$. For each neuron, probability density functions associated with each whisker were estimated nonparametrically from the spike count histogram (Fig. 6G). The identity of the most likely single whisker stimulus represented by the spiking activity could then be predicted using a Bayesian decoding strategy. We found that the distribution of decoding accuracies in the EB group was significantly different from the SC group, displaying a shift toward improved performance in discriminating between the four most dominant whiskers in their receptive fields compared to the SC group (BW, SW1, SW2, and SW3; Fig. $6 H ; p=0.002, \mathrm{~d}=$ 0.603 , permutation test). Thus, although neural response distributions are shifted toward lower spike count values across whisker stimuli in the EB group relative to the SC group, the response distributions associated with the deflection of different whiskers are less overlapping, leading to improved discrimination between multiple whiskers in the receptive field.

\section{Somatotopic tuning curves are spatially sharpened following early blindness, especially along the horizontal axis}

We compared the 2D spatial configuration of receptive fields in SC and EB animals, which included the response magnitude of the BW (center of the receptive field) and the eight $1^{\circ}$ SWs; mean receptive fields are shown in Figure $7 A$. Sharpness of tuning was quantified as the tuning width index (see Materials and Methods). Distribution of tuning width indices were shifted toward lower values in EB animals than in SC animals, indicating sharper tuning (Fig. $7 B ; p=0.008$, outliers excluded: $p=0.024$, Kolmogorov-Smirnov test). An alternate explanation for the relative shift in the tuning width index distribution could be that whiskerevoked responses were lost at some SW positions but preserved at other positions in EB versus SC animals, which would result in an alteration of receptive field shape. However, we found that distributions of receptive field shape were not significantly different between the two groups- both SC and EB distributions were skewed toward anisotropic receptive field shapes, mostly elongated along the row axis (Fig. $7 C ; p=0.911$, Kolmogorov-Smirnov test). Further, when all receptive fields were aligned along the major axis, we found that mean responses evoked by SWs $\left(1^{\circ}, 2^{\circ}\right.$, $3^{\circ}$ ) were relatively suppressed along both the major and minor axes (major axis: $p=5.0 \times 10^{-04}$, minor axis: $p=5.5 \times 10^{-03}$, unpaired $t$ test). Thus, spatial sharpening occurred along both horizontal and vertical axes of receptive fields in EB animals. Mean normalized somatotopic tuning curves for SC and EB groups were computed after collapsing along either the vertical axis (Fig. 7D) or the horizontal axis (Fig. 7E). EB tuning curves were significantly sharper in both cases (vertical: $p=0.032$, horizontal: $p=6.62 \times 10^{-08}$, 2-way ANOVA, main effect of experimental group); however, the median magnitude of relative suppression for EB animals compared to SC animals was 1.42 times greater along the horizontal axis than along the vertical axis across the $1^{\circ}, 2^{\circ}$, and $3^{\circ} \mathrm{SW}$ positions.

\section{S1 decoding accuracy for classifying whisker stimulus location is improved following early blindness, especially along the rostrocaudal axis of the snout}

We applied decoding analyses to evaluate the information contained in S1 neuronal populations of SC and EB animals regarding the location of a whisker stimulus on the mystacial pad. For each group, recorded neurons were pooled to generate a pseudopopulation, and a minimum distance classifier (Foffani and Moxon, 2004) was trained using a leave-one-out cross-validation method. The classifier was then used to predict the identity of the whisker stimulus that occurred on each trial in terms of location along either the dorsoventral axis (Fig. 8A; one of four possible whisker rows: A, B, C or D) or the rostrocaudal axis (Fig. $8 B$; one of four possible whisker arcs: $0,1,2$ or 3 ) of the snout. Confusion matrices (Fig. $8 C$ ) show the percentage of trials classified into each of the four classes (rows or arcs) for SC and EB populations of neurons, across all iterations. For row classification (ROW), the majority of values fell along the diagonal for both SC and EB populations, indicating that most trials were correctly classified by the decoder (left, top and bottom). For the EB population, improvements in row classification performance observed were mainly due to decreased misclassification of trials corresponding to the upper rows of whiskers (rows A and B). For arc classification (ARC), differences in the performance of the classifier for SC and EB populations were readily apparent. For the SC population, trials corresponding to adjacent arcs were frequently confused with each other across all arcs (arcs $0-3)$. In contrast, for the EB population, a larger proportion of trials were correctly classified, visible as the increased proportion of values on the diagonal and decreased proportion of values off the diagonal in the confusion matrix. As noted previously (Fig. $3 J$ ), the distributions of BWs of the recorded neurons were very similar between SC and EB groups, so these differences in population decoding performance could not be attributed to differences in tuning preferences of the neurons sampled. Decoding accuracies were significantly greater than chance performance (computed by shuffling trial labels; SC ROW: $p=9.99 \times 10^{-04}, \mathrm{~d}=53.9, \mathrm{~EB}$ ROW: $p=9.99 \times 10^{-04}, \mathrm{~d}=84.8$, SC ARC: $p=9.99 \times 10^{-04}$, $\mathrm{d}=16.7, \mathrm{~EB}$ ARC: $p=9.99 \times 10^{-04}, \mathrm{~d}=71.1$, permutation test) in all cases (Fig. 8D). Within each experimental group, row classification performance was greater than arc classification performance $\left(\right.$ SC: $p=9.99 \times 10^{-04}, \mathrm{~d}=16.8, \mathrm{~EB}: p=9.99 \times 10^{-04}$, $\mathrm{d}=30.3$, permutation test). The distribution of decoding accuracies for the $\mathrm{EB}$ population compared to the SC population across all iterations was shifted toward significantly higher values for both row classification performance $\left(p=9.99 \times 10^{-04}, \mathrm{~d}=\right.$ 1.82 , permutation test) and arc classification performance $(p=$ $9.99 \times 10^{-04}, \mathrm{~d}=7.80$, permutation test), but the separation between SC and EB distributions was greater for arc classification performance (Fig. 8D). Therefore, the improvement in decoding 
A

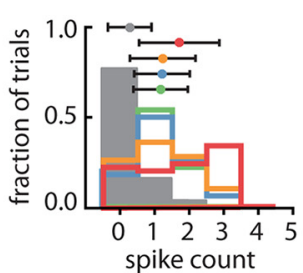

C
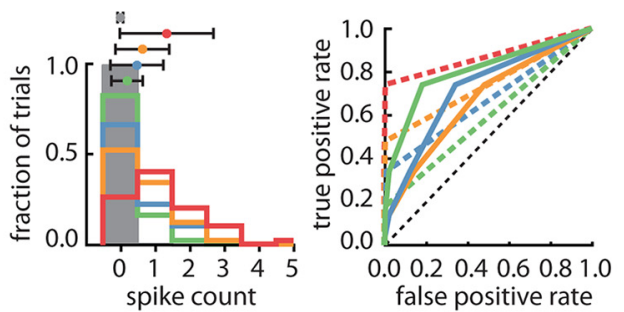

E

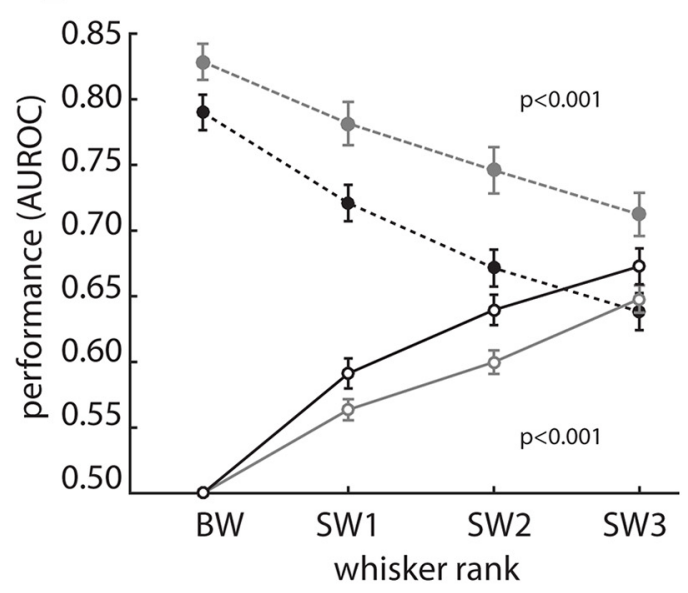

G
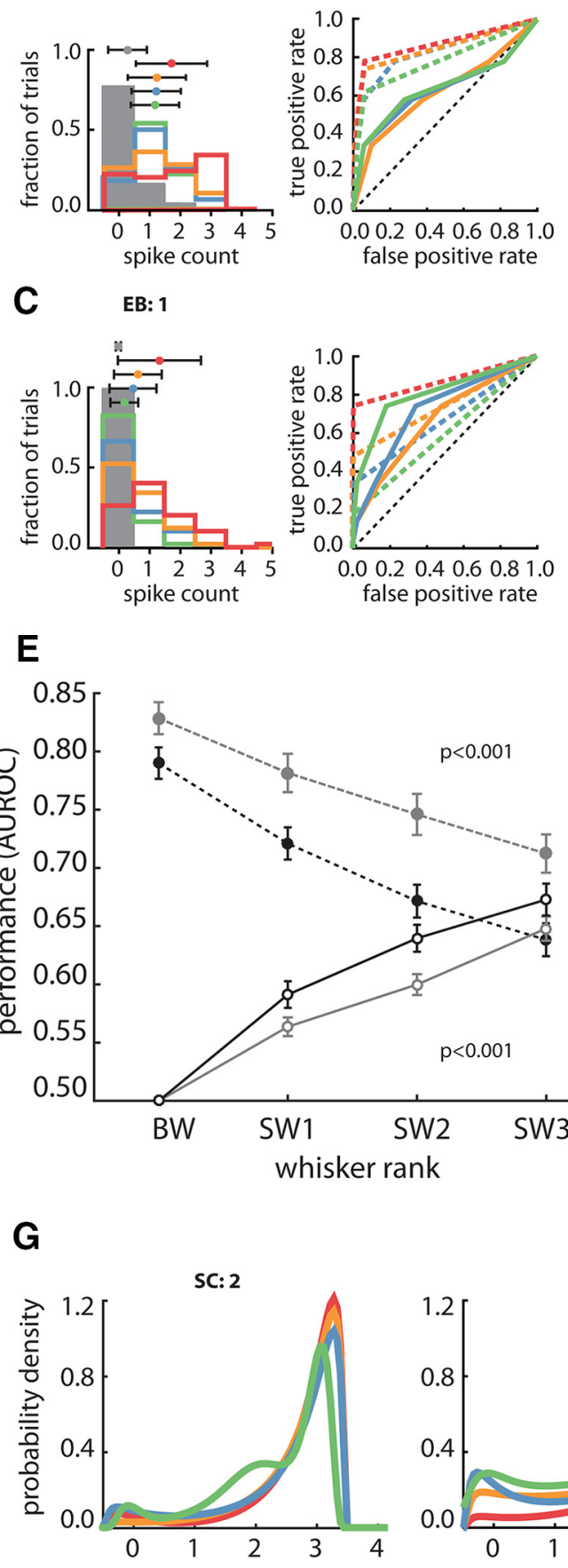

false positive rate

0.20 .40 .60 .81 .0

\section{$\mathbf{F}$}

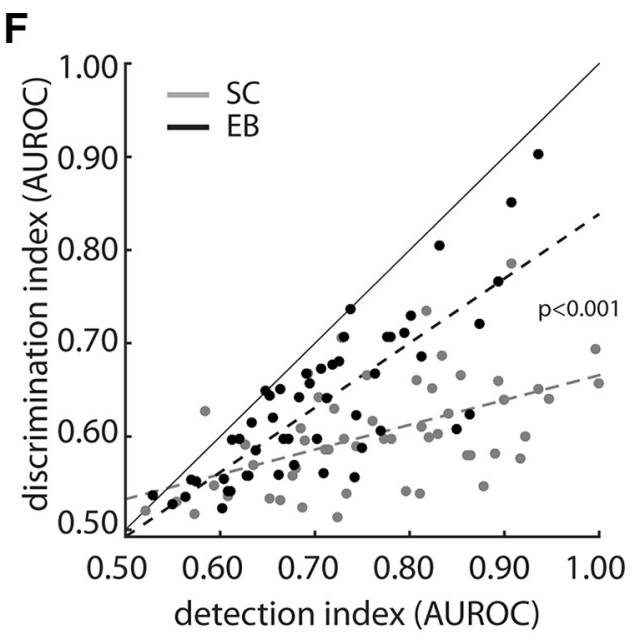

H
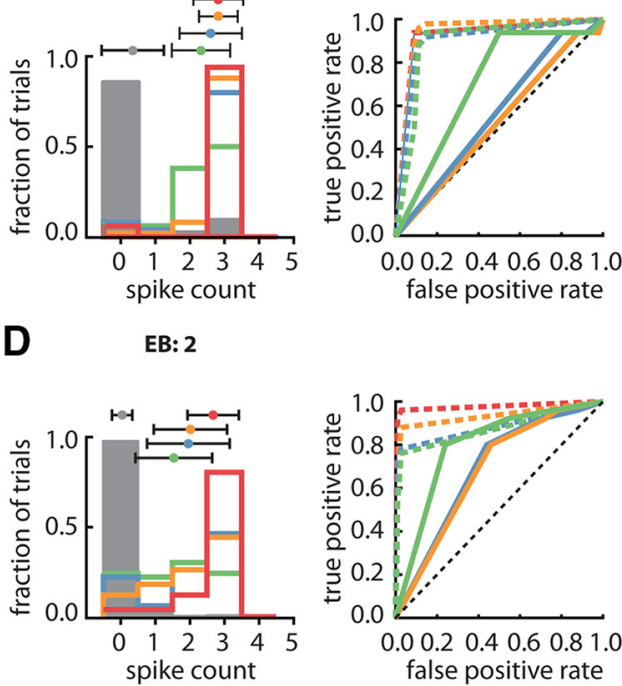

D EB: 2

D EB: 2
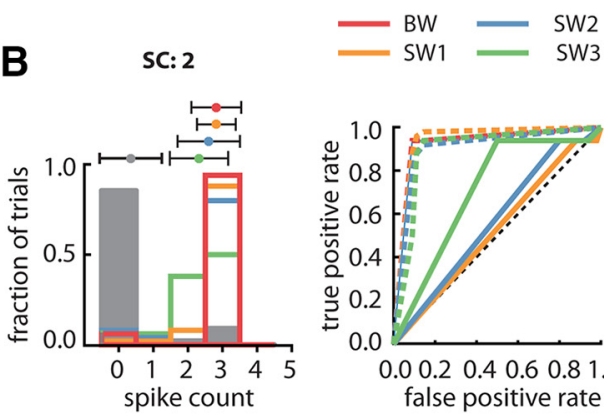

0.00 .20 .40 .60 .81$.

0.00 .40 .60 .81 .0
false positive rate

(2)

Figure 6. Quantification of the neuronal detection and discrimination performance. $A, B$, Spike count distributions (BW, red; SW1, yellow; SW2, blue; SW3, green; and spontaneous, gray) for example S1 neurons from the SC populations (left) and ROC curves (right) generated from these spike count distributions for detection performance (BW/SW1/SW2/SW3 vs spontaneous activity, dashed lines) and discrimination performance (BW vs SW1/SW2/SW3, solid lines). Examples show a neuron with relatively low mean firing rate $(\boldsymbol{A})$ and a neuron with a relatively high mean firing rate $(\boldsymbol{B})$ in the recorded population. $\boldsymbol{C}, \boldsymbol{D}$, Spike count distributions for example $S 1$ neurons with relatively low mean firing rate $(\boldsymbol{C})$ and high mean firing rate $(\boldsymbol{D})$ from EB population and the corresponding ROC curves. Same conventions as in $\boldsymbol{A}$ and $\boldsymbol{B}$. Mean \pm 1 SD is shown above each distribution. For neurons with both high and low firing rates, the spike count distribution associated with the BW was better separated from spike count distributions associated with the SWs in EB animals compared with SC animals. $E$, Mean AUROC values for neuronal discrimination of BW from SW1/SW2/SW3 (solid lines) and for neuronal detection of BW/SW1/SW2/SW3 from spontaneous activity (dashed lines). For both SC and EB neurons, performance for discrimination of the BW from SWs was lower than detecting BW deflection relative to spontaneous activity. Detection performance for EB neurons was decreased relative to SC neurons; however, discrimination performance was improved. $\boldsymbol{F}$, Relationship between detectability and discriminability for single units in S1. Mean AUROC values for neural discrimination (BW vs S1/SW2/SW3) are plotted as a function of the mean AUROC values for neural detection (spontaneous vs BW/SW1/SW2/SW3). The best-fitting line through mean AUROC values for EB animals (dashed black line) was steeper ( $p<0.001$, ANCOVA) than that for SC animals (dashed gray line) and discriminability was relatively enhanced for $\mathrm{S1}$ neurons in EB animals compared with SC animals for a given level of stimulus detectability. $\mathbf{G}$, Probability density functions corresponding to spike count histograms shown in $\boldsymbol{B}(\mathrm{SC}$, left) and $\boldsymbol{D}$ (EB, right), respectively. $\boldsymbol{H}$, Distributions of Bayesian classifier performance for the SC (gray) and EB (black) groups show a significant difference in multiple whisker discrimination between the two experimental groups. Level of chance performance is $25 \%$. 


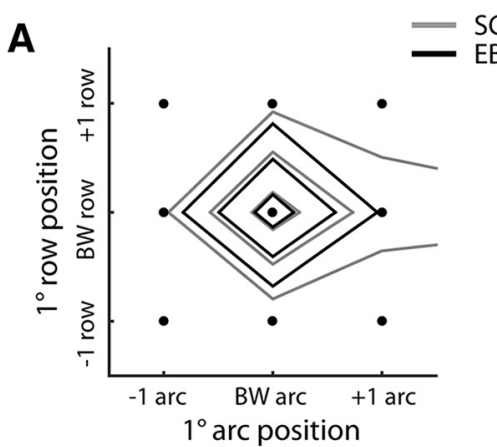

B

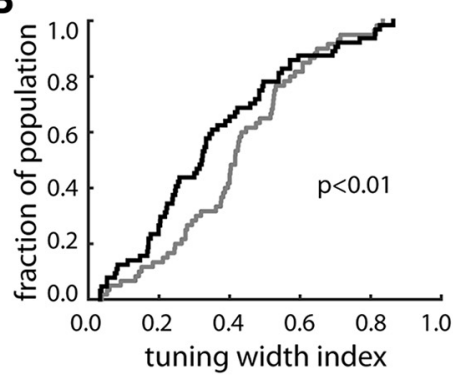

C

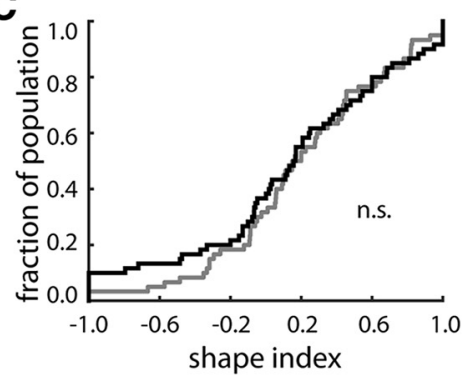

D

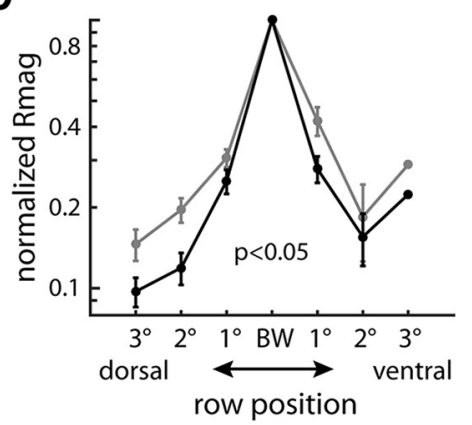

E

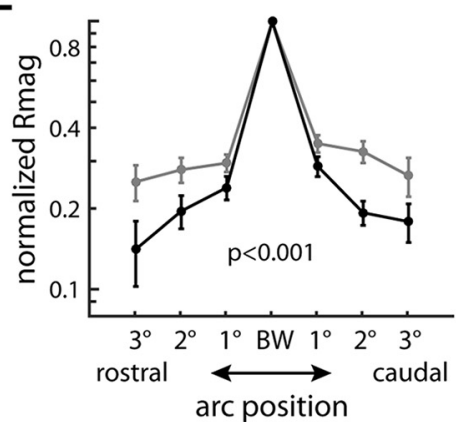

Figure 7. Spatial configuration of receptive fields for neurons in $\mathrm{S} 1$ in $\mathrm{EB}$ and $\mathrm{SC}$ animals. $A$, Average $2 D$ receptive field for $S C$ (gray) and EB (black) neurons. Only SW positions immediately adjacent to the $\mathrm{BW}\left(1^{\circ} \mathrm{SW}\right)$ are depicted here. The contour plot is centered on the BW. Contour lines show $50 \%, 70 \%$, and $90 \%$ response levels (relative to the BW). Mean receptive field contours in EB animals are contracted compared with those of SC animals. B, Cumulative distribution of tuning width index for all recorded neurons. Receptive fields of $E B$ neurons were more performance in EB versus SC animals was greatest for whisker stimulus locations along the rostrocaudal axis of the snout.

In summary, we found that neural coding of whisker-mediated touch was altered in animals that experienced vision loss early in development compared with SCs. Whisker stimuli evoked lower magnitude responses in EB animals, but the relative suppression of whisker-evoked responses was greater for nonpreferred stimuli (SWs) than the preferred stimulus (BW) such that S1 neurons were more selective to whisker-mediated touch in EB animals. These changes in response properties led to decreased performance on whisker stimulus detection by S1 neurons, but enhanced their performance on whisker stimulus discrimination. For the population of S1 neurons, whisker stimulus location on the mystacial pad could be decoded with greater accuracy in EB animals, particularly along the rostrocaudal axis of the snout. Overall, the changes in sensory coding observed in S1 after early blindness were consistent with enhanced spatial discrimination of tactile stimuli.

\section{Discussion}

Previous studies have reported that barrel fields in S1 are expanded in neonatally enucleated mice and rats (Bronchti et al., 1992; Rauschecker et al., 1992; Zheng and Purves, 1995). Likewise, our laboratory has demonstrated an increase in the total cortical territory occupied by S1 in EB versus SC opossums (Karlen and Krubitzer, 2009). There have been a few reports of improved tactile or auditory performance after early vision loss (Rauschecker and Kniepert, 1994; Toldi et al., 1994; Lomber et al., 2010; Meredith et al., 2011) accompanied in some cases by greater response selectivity of neurons in higher order cortical areas, which play a role in processing multisensory inputs (Korte and Rauschecker, 1993). More recently, alterations in synaptic function have been described in primary cortical areas associated with spared modalities, including S1 (Goel et al., 2006; Jitsuki et al., 2011; Zheng et al., 2014). These changes can even occur in adults following relatively short periods of visual deprivation (up to 1 week) (Petrus et al., 2014; Meng et al., 2015, 2017; Nakajima et al., 2016), with different effects on spared and deprived sensory cortices (He et al., 2012; Petrus et al., 2014). However, to date, it is unknown whether and how long-term unimodal sensory loss affects sensory processing at the level of single neurons and populations of neurons in primary cortical areas of the remaining sensory modalities.

We have demonstrated that neural coding of whisker-mediated touch in $\mathrm{S} 1$ is altered in animals that experienced loss of vision very early in development. We found that neurons in S1 of EB animals exhibited an overall reduction in the magnitude of responses to single whisker stimuli for both the preferred stimulus (BW) and the nonpreferred stimuli (SW). Suppression of neural responses to whisker stimuli in our study were not attributable to an overall decrease in cortical excitability, differences in anesthetic state, or a lack of active tactile exploration (Guic et al., 2008, Alwis and Rajan, 2013) following early blindness. Further, suppression was specific to whisker-evoked responses, combined with an increased selectivity of neurons in S1 for single whisker

$\longleftarrow$

sharply tuned than those of SC neurons. $C$, Cumulative distribution of shape index for all recorded neurons. Receptive fields of SC and EB neurons did not significantly differ in shape. $\boldsymbol{D}, \boldsymbol{E}$, Mean tuning curve for $S C$ and $E B$ neurons collapsed along the vertical $(\boldsymbol{D})$ and horizontal $(\boldsymbol{E})$ axis of $\boldsymbol{A}$ for SW positions. The $2^{\circ}$ and $3^{\circ} \mathrm{SW}$ positions are shown in addition to the $1^{\circ} \mathrm{SW}$ positions. The mean EB tuning curve is sharpened relative to the mean $S C$ tuning curve along both the horizontal axis and the vertical axis, but to a greater extent along the horizontal axis. 
A

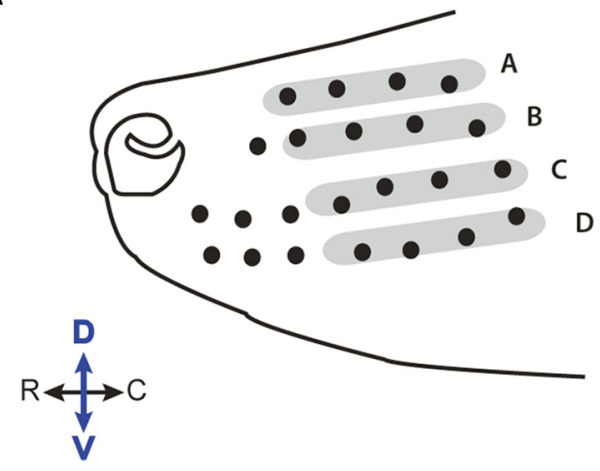

B

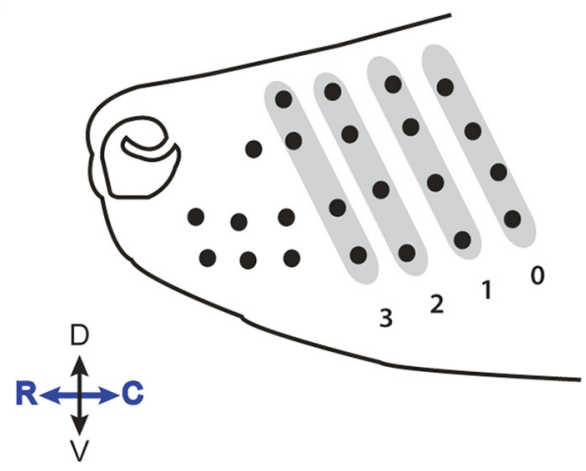

C

ROW

ARC

actual stimulus

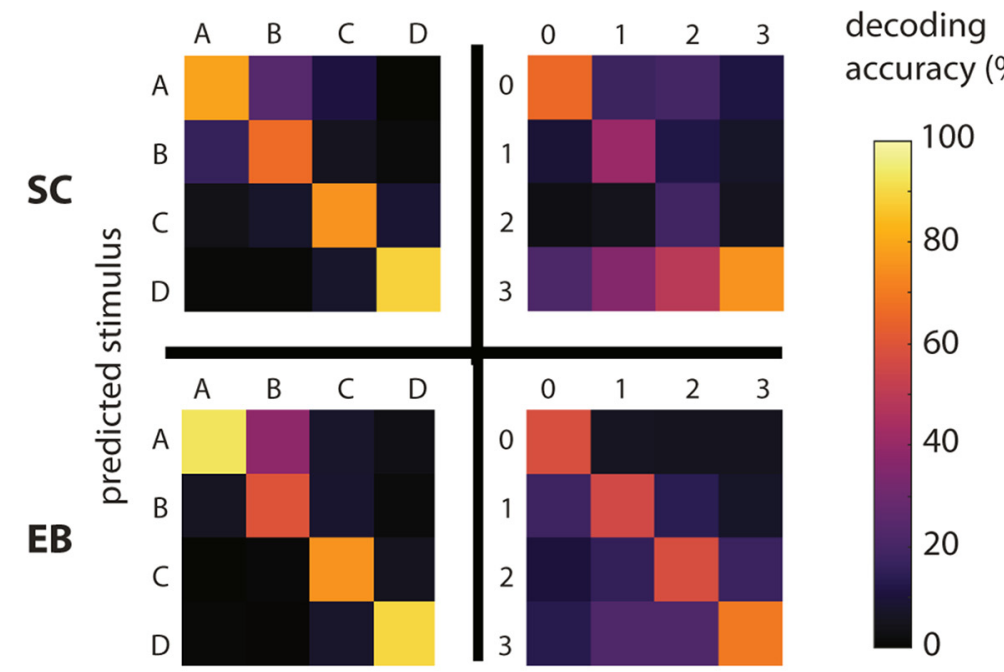

D

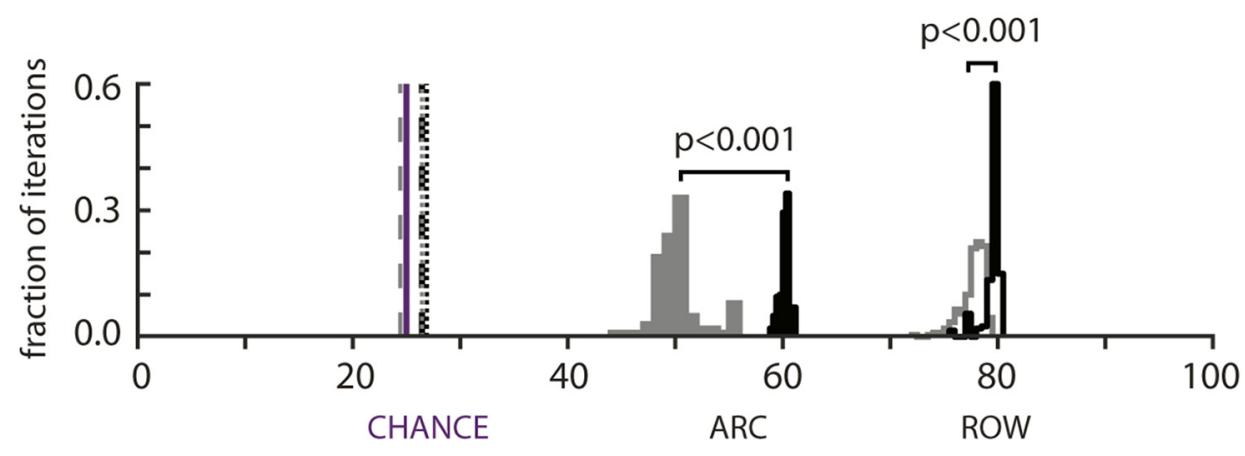

decoding accuracy (\% correct)

Figure 8. Population decoding of whisker stimulus position in $E B$ and $S C$ animals. $A, B$, Classification of whisker identity for positions along the dorsoventral axis (rows $A-D ; A)$, and along the rostrocaudal axis $(\operatorname{arcs} 0-3 ; \boldsymbol{B})$ for population decoding analysis. $\boldsymbol{C}$, Confusion matrices for classifier performance based on $\mathrm{SC}$ and EB populations of neurons. Actual stimuli presented are shown along the $x$-axis and predicted stimuli are shown along the $y$-axis in all cases. The color scale indicates decoding accuracy (percentage correct), with lighter colors indicating better performance. As evident from a higher proportion of values on the diagonal of the confusion matrix, whisker rows were classified correctly more frequently than whisker arcs in both the SC and EB groups. Between groups, improvements in classifier performance in $\mathrm{EB}$ animals relative to $\mathrm{SC}$ animals are visible and particularly notable for the classification of whisker arcs. $D$, Distributions of population decoding accuracy for SC (gray) and EB (black) neurons for whisker position along the dorsoventral axis (ROW) and the rostrocaudal axis (ARC) relative to chance performance (theoretical: solid vertical line at 25\%; shuffled class labels: dashed lines are row classification and dotted lines are arc classification). Classifier performance was significantly above chance in all cases. Row classification performance was greater than arc classification performance for neurons within both SC and EB groups. Decoding accuracy was significantly greater for EB neurons compared with SC neurons for row classification as well as arc classification, though the difference in performance between the two groups was much greater for arc classification. 
stimuli. Greater stimulus selectivity could, in theory, result from either an attenuation of SW-evoked responses or an increase in BW-evoked responses. We found that suppression of whiskerevoked responses in EB animals relative to SC animals was nonuniform across the receptive field, such that SW-evoked responses were suppressed to a greater extent than BW-evoked responses, resulting in sharper tuning curves. Interestingly, our findings resemble some forms of plasticity previously reported in the $\mathrm{S} 1$ whisker representation, which are functionally distinct from Hebbian forms of plasticity (for review, see Feldman and Brecht, 2005) typically observed in studies involving manipulations that create competition among sensory inputs within the whisker system (e.g., deprivation of a subset of whisker inputs though trimming, plucking, or follicle lesion). Polley et al. (2004) found that prolonged exposure of rats to complex, naturalistic environments in adulthood resulted in the contraction of the functional representation of individual whiskers, suppression of whisker-evoked responses, and smaller, sharper receptive fields for neurons in S1. Further, when adult rats were allowed brief periods of whisker-guided exploration in a novel environment after deprivation of all but a single whisker, the direction of Hebbian plasticity was reversed, causing a contraction of the functional representation of the spared whisker rather than its expansion (Polley et al., 1999). A common theme between our study and the work by Polley et al. $(1999,2004)$ is that plasticity is observed in the somatosensory system of animals that have been subjected to a manipulation that can be expected to increase the animals' dependence on the whisker system-through vision loss in our study, and through transfer to a more tactilely complex environment in the studies by Polley et al. (for review, see Frostig, 2006). In both cases, the net effect was a refinement in the functional organization of the S1 whisker representation such that neural coding of single whisker stimuli was sparser and more metabolically efficient, and displayed increased spatial precision. In EB animals, we found that the ability of S1 neurons to discriminate between neighboring whiskers was enhanced at the expense of their ability to detect single whisker stimuli. Similar changes in barrel cortex have been previously linked to enhanced sensory processing on shorter time scales, specifically during arousal (Castro-Alamancos and Oldford, 2002; Hirata and CastroAlamancos, 2011) and following sensory adaptation (Wang et al., 2010; Ollerenshaw et al., 2014). Our results suggest that plasticity after sensory loss is not necessarily universally adaptive, but may involve a compromise between certain functions, at least within a given brain region associated with a spared sensory modality. The changes in S1 may reflect a redistribution of function in the brain, given that cortical and subcortical areas normally associated with vision are also recruited for somatosensory processing in EB animals (Kahn and Krubitzer, 2002; Karlen et al., 2006). However, these opposite effects on neuronal performance in $\mathrm{S} 1$ may also reflect a genuine trade-off in tactile function; there have been reports of both deficits and enhancements in the behavioral performance of blind individuals depending on the nature of the tactile task used (Sterr et al., 1998a,b, 2003; Alary et al., 2009). To what extent these changes in neural coding of whisker-mediated touch in S1 after early blindness impact behavioral detectability and discriminability of stimuli remains to be investigated. Results from the current study allow us to generate testable hypotheses in this regard. Additional research is also necessary to determine the contribution of plasticity occurring at subcortical levels to the effects observed in S1.

It is possible that the effects of suppression and spatial sharpening are correlates of perceptual learning (Gold and Watanabe,
2010) in S1, which confers long-term experience-dependent improvements in the ability to process tactile information after early blindness (Wong et al., 2011). Previous studies have demonstrated that exposure to passive stimulation of a single whisker results in the suppression and contraction of its functional representation (Welker et al., 1992; Gdalyahu et al., 2012), along with an increase in cortical inhibition (Welker et al., 1989; Knott et al., 2002), possibly due to learned habituation to repetitive stimulation or as a result of homeostatic processes (Welker et al., 1992; Polley, 2002; Foeller and Feldman, 2004). EB animals are forced to depend on whisker-mediated touch as the primary means of navigating their environment using spatial cues. Thus, a use-dependent increase in whisker stimulation after early blindness is one potential mechanism that could drive functional plasticity in the S1 whisker representation.

A noteworthy aspect of somatosensory plasticity following early blindness was the anisotropy observed in receptive field changes and population decoding performance for S1 neurons, such that discrimination of whisker stimulus position was enhanced to a greater extent along the horizontal/rostrocaudal axis of the snout, aligned with the primary direction of natural whisker motion. This could reflect a row bias inherent to the structural and functional organization of the S1 whisker representation (Armstrong-James and Fox, 1987; Bernardo et al., 1990; Lustig et al., 2013; Ramamurthy and Krubitzer, 2016). In addition, simulations of whisking during exploratory activity in rats indicate that whiskers within the same row (same horizontal axis) are most likely to come in simultaneous contact with a surface (Hobbs et al., 2015). Given that mystacial pad morphology and whisking behavior are highly conserved across mammals (Brecht et al., 1997; Grant et al., 2013; Ramamurthy and Krubitzer, 2016), it is reasonable to postulate that similar patterns of whisker contact during exploration by short-tailed opossums may drive use-dependent anisotropies of receptive field alterations in EB versus SC animals.

In the current study, we found that overall levels of tactile experience did not differ significantly between EB and SC groups across all developmental stages tested. We cannot rule out the possibility that context-dependent differences between sighted and blind animals in whisking strategies during exploration (Arkley et al., 2014) may contribute to differences in S1 neural response properties and receptive field structure. However, our findings suggest that factors other than increased whisker stimulation could play a role in somatosensory plasticity following early blindness. For example, tactile experience may need to be accompanied by focused attention to whisker stimuli in order for this plasticity to occur, which may be more likely after early blindness, given the animals' increased dependence on the somatosensory system. Alternatively, or in addition, somatosensory plasticity may have been facilitated by the loss of vision itself (Goldreich and Kanics, 2003), independent of tactile experience. For example, there is some evidence that vision loss, rather than whisker-mediated tactile experience, leads to barrel field expansion in neonatally enucleated rats via epigenetic mechanisms that influence the growth rate and arborization patterns of somatosensory thalamocortical axons (Fetter-Pruneda et al., 2013). Future research incorporating additional sensory deprivation (whisker trimming and dark rearing) or enrichment paradigms with sighted and blind animals will help further clarify the relative effects of tactile experience versus vision loss on neural coding in S1 following early blindness. 


\section{References}

Alary F, Duquette M, Goldstein R, Elaine Chapman C, Voss P, La Buissonnière-Ariza V, Lepore F (2009) Tactile acuity in the blind: a closer look reveals superiority over the sighted in some but not all cutaneous tasks. Neuropsychologia 47:2037-2043. CrossRef Medline

Alwis DS, Rajan R (2013) Environmental enrichment causes a global potentiation of neuronal responses across stimulus complexity and lamina of sensory cortex. Front Cell Neurosci 7:124. CrossRef Medline

Arkley K, Grant Robyn A, Mitchinson B, Prescott TJ (2014) Strategy change in vibrissal active sensing during rat locomotion. Curr Biol 24:1507-1512. CrossRef Medline

Armstrong-James M, Fox K (1987) Spatiotemporal convergence and divergence in the rat S1 "barrel" cortex. J Comp Neurol 263:265-281. CrossRef Medline

Bavelier D, Neville HJ (2002) Cross-modal plasticity: where and how? Nat Rev Neurosci 3:443-452. CrossRef Medline

Bernardo KL, McCasland JS, Woolsey TA, Strominger RN (1990) Local intra- and interlaminar connections in mouse barrel cortex. J Comp Neurol 291:231-255. CrossRef Medline

Brecht M, Preilowski B, Merzenich MM (1997) Functional architecture of the mystacial vibrissae. Behav Brain Res 84:81-97. CrossRef Medline

Britten KH, Shadlen MN, Newsome WT, Movshon JA (1992) The analysis of visual motion: a comparison of neuronal and psychophysical performance. J Neurosci 12:4745-4765. CrossRef Medline

Bronchti G, Schönenberger N, Welker E, Van der Loos H (1992) Barrelfield expansion after neonatal eye removal in mice. Neuroreport 3:489-492. CrossRef Medline

Bronchti G, Heil P, Sadka R, Hess A, Scheich H, Wollberg Z (2002) Auditory activation of "visual" cortical areas in the blind mole rat (Spalax ehrenbergi). Eur J Neurosci 16:311-329. CrossRef Medline

Butler BE, Lomber SG (2013) Functional and structural changes throughout the auditory system following congenital and early-onset deafness: implications for hearing restoration. Front Syst Neurosci 7:92. CrossRef Medline

Castro-Alamancos MA, Oldford E (2002) Cortical sensory suppression during arousal is due to the activity-dependent depression of thalamocortical synapses. J Physiol 541:319-331. CrossRef Medline

Chabot N, Robert S, Tremblay R, Miceli D, Boire D, Bronchti G (2007) Audition differently activates the visual system in neonatally enucleated mice compared with anophthalmic mutants. Eur J Neurosci 26:23342348. CrossRef Medline

Dooley JC, Franca JG, Seelke AM, Cooke DF, Krubitzer LA (2013) A connection to the past: Monodelphis domestica provides insight into the organization and connectivity of the brains of early mammals. J Comp Neurol 521:3877-3897. CrossRef Medline

Erchova IA, Lebedev MA, Diamond ME (2002) Somatosensory cortical neuronal population activity across states of anaesthesia. Eur J Neurosci 15: 744-752. Medline

Feldman DE, Brecht M (2005) Map plasticity in somatosensory cortex. Science 310:810-815. CrossRef Medline

Fetter-Pruneda I, Geovannini-Acuña H, Santiago C, Ibarrarán-Viniegra AS, Martínez-Martínez E, Sandoval-Velasco M, Uribe-Figueroa L, PadillaCortés P, Mercado-Célis G, Gutiérrez-Ospina G (2013) Shifts in developmental timing, and not increased levels of experience-dependent neuronal activity, promote barrel expansion in the primary somatosensory cortex of rats enucleated at birth. PLoS One 8:e54940. CrossRef Medline

Foeller E, Feldman DE (2004) Synaptic basis for developmental plasticity in somatosensory cortex. Curr Opin Neurobiol 14:89-95. CrossRef Medline

Foffani G, Moxon KA (2004) PSTH-based classification of sensory stimuli using ensembles of single neurons. J Neurosci Methods 135:107-120. CrossRef Medline

Friedberg MH, Lee SM, Ebner FF (1999) Modulation of receptive field properties of thalamic somatosensory neurons by the depth of anesthesia. J Neurophysiol 81:2243-2252. CrossRef Medline

Frostig RD (2006) Functional organization and plasticity in the adult rat barrel cortex: moving out-of-the-box. Curr Opin Neurobiol 16:445-450. CrossRef Medline

Gallyas F (1979) Silver staining of myelin by means of physical development. Neurol Res 1:203-209. CrossRef Medline

Gdalyahu A, Tring E, Polack PO, Gruver R, Golshani P, Fanselow MS, Silva AJ, Trachtenberg JT (2012) Associative fear learning enhances sparse network coding in primary sensory cortex. Neuron 75:121-132. CrossRef Medline

Goel A, Jiang B, Xu LW, Song L, Kirkwood A, Lee HK (2006) Cross-modal regulation of synaptic AMPA receptors in primary sensory cortices by visual experience. Nat Neurosci 9:1001-1003. CrossRef Medline

Gold JI, Watanabe T (2010) Perceptual learning. Curr Biol 20:R46-R48. CrossRef Medline

Goldreich D, Kanics IM (2003) Tactile acuity is enhanced in blindness. J Neurosci 23:3439-3445. CrossRef Medline

Grant RA, Haidarliu S, Kennerley NJ, Prescott TJ (2013) The evolution of active vibrissal sensing in mammals: evidence from vibrissal musculature and function in the marsupial opossum Monodelphis domestica. J Exp Biol 216:3483-3494. CrossRef Medline

Green DM, Swets JA (1966) Signal detection theory and psychophysics. New York, NY: Wiley.

Guic E, Carrasco X, Rodríguez E, Robles I, Merzenich MM (2008) Plasticity in primary somatosensory cortex resulting from environmentally enriched stimulation and sensory discrimination training. Biol Res 41:425437. CrossRef Medline

Hallgren KA (2012) Computing inter-rater reliability for observational data: an overview and tutorial. Tutor Quant Methods Psychol 8:23-34. CrossRef Medline

He K, Petrus E, Gammon N, Lee HK (2012) Distinct sensory requirements for unimodal and cross-modal homeostatic synaptic plasticity. J Neurosci 32:8469-8474. CrossRef Medline

Hentschke H, Stüttgen MC (2011) Computation of measures of effect size for neuroscience data sets. Eur J Neurosci 34:1887-1894. CrossRef Medline

Hewitt B, Yap MH, Grant R (2016) Manual whisker annotator (mwa): a modular open-source tool. Journal of Open Research Software 4:e16.

Hirata A, Castro-Alamancos MA (2011) Effects of cortical activation on sensory responses in barrel cortex. J Neurophysiol 105:1495-1505. CrossRef Medline

Hobbs JA, Towal RB, Hartmann MJ (2015) Probability distributions of whisker-surface contact: quantifying elements of the rat vibrissotactile natural scene. J Exp Biol 218:2551-2562. CrossRef Medline

Huffman KJ, Nelson J, Clarey J, Krubitzer L (1999) Organization of somatosensory cortex in three species of marsupials, Dasyurus hallucatus, Dactylopsila trivirgata, and Monodelphis domestica: neural correlates of morphological specializations. J Comp Neurol 403:5-32. CrossRef Medline

Hunt DL, Yamoah EN, Krubitzer L (2006) Multisensory plasticity in congenitally deaf mice: how are cortical areas functionally specified? Neuroscience 139:1507-1524. CrossRef Medline

Izraeli R, Koay G, Lamish M, Heicklen-Klein AJ, Heffner HE, Heffner RS, Wollberg Z (2002) Cross-modal neuroplasticity in neonatally enucleated hamsters: structure, electrophysiology and behaviour. Eur J Neurosci 15:693-712. CrossRef Medline

Jitsuki S, Takemoto K, Kawasaki T, Tada H, Takahashi A, Becamel C, Sano A, Yuzaki M, Zukin RS, Ziff EB, Kessels HW, Takahashi T (2011) Serotonin mediates cross-modal reorganization of cortical circuits. Neuron 69:780-792. CrossRef Medline

Kahn DM, Krubitzer L (2002) Massive cross-modal cortical plasticity and the emergence of a new cortical area in developmentally blind mammals. Proc Natl Acad Sci U S A 99:11429-11434. CrossRef Medline

Kahn DM, Huffman KJ, Krubitzer L (2000) Organization and connections of V1 in Monodelphis domestica. J Comp Neurol 428:337-354. CrossRef Medline

Karlen SJ, Krubitzer L (2009) Effects of bilateral enucleation on the size of visual and nonvisual areas of the brain. Cereb Cortex 19:1360-1371. CrossRef Medline

Karlen SJ, Kahn DM, Krubitzer L (2006) Early blindness results in abnormal corticocortical and thalamocortical connections. Neuroscience 142:843858. CrossRef Medline

Knott GW, Quairiaux C, Genoud C, Welker E (2002) Formation of dendritic spines with GABAergic synapses induced by whisker stimulation in adult mice. Neuron 34:265-273. CrossRef Medline

Korte M, Rauschecker JP (1993) Auditory spatial tuning of cortical neurons is sharpened in cats with early blindness. J Neurophysiol 70:1717-1721. CrossRef Medline

Landers M, Philip Zeigler H (2006) Development of rodent whisking: tri- 
geminal input and central pattern generation. Somatosens Mot Res 23:110. CrossRef Medline

Landis JR, Koch GG (1977) The measurement of observer agreement for categorical data. Biometrics 33:159-174. CrossRef Medline

Lomber SG, Meredith MA, Kral A (2010) Cross-modal plasticity in specific auditory cortices underlies visual compensations in the deaf. Nat Neurosci 13:1421-1427. CrossRef Medline

Lustig BR, Friedman RM, Winberry JE, Ebner FF, Roe AW (2013) Voltagesensitive dye imaging reveals shifting spatiotemporal spread of whiskerinduced activity in rat barrel cortex. J Neurophysiol 109:2382-2392. CrossRef Medline

Meng X, Kao JP, Lee HK, Kanold PO (2015) Visual deprivation causes refinement of intracortical circuits in the auditory cortex. Cell Rep 12:955964. CrossRef Medline

Meng X, Kao JP, Lee HK, Kanold PO (2017) Intracortical circuits in thalamorecipient layers of auditory cortex refine after visual deprivation. eNeuro 4:ENEURO.0092-17.2017. CrossRef Medline

Meredith MA, Kryklywy J, McMillan AJ, Malhotra S, Lum-Tai R, Lomber SG (2011) Crossmodal reorganization in the early deaf switches sensory, but not behavioral roles of auditory cortex. Proc Natl Acad Sci U S A 108: 8856-8861. CrossRef Medline

Mitchinson B, Grant RA, Arkley K, Rankov V, Perkon I, Prescott TJ (2011) Active vibrissal sensing in rodents and marsupials. Philos Trans R Soc Lond B Biol Sci 366:3037-3048. CrossRef Medline

Molnár Z, Blakemore C (1995) How do thalamic axons find their way to the cortex? Trends Neurosci 18:389-397. CrossRef Medline

Molnár Z, Knott GW, Blakemore C, Saunders NR (1998) Development of thalamocortical projections in the south american gray short-tailed opossum (Monodelphis domestica). J Comp Neurol 398:491-514. CrossRef Medline

Nakajima W, Jitsuki S, Sano A, Takahashi T (2016) Sustained enhancement of lateral inhibitory circuit maintains cross modal cortical reorganization. PLoS One 11:e0149068. CrossRef Medline

Ollerenshaw DR, Zheng HJV, Millard DC, Wang Q, Stanley GB (2014) The adaptive trade-off between detection and discrimination in cortical representations and behavior. Neuron 81:1152-1164. CrossRef Medline

Pagliardini S, Greer JJ, Funk GD, Dickson CT (2012) State-dependent modulation of breathing in urethane-anesthetized rats. J Neurosci 32:1125911270. CrossRef Medline

Petrus E, Isaiah A, Jones AP, Li D, Wang H, Lee HK, Kanold PO (2014) Crossmodal induction of thalamocortical potentiation leads to enhanced information processing in the auditory cortex. Neuron 81:664-673. CrossRef Medline

Polley DB (2002) The representation of the body surface and its plasticity in the adult barrel cortex. Neuroscience 2005;134:355-359.

Polley DB, Chen-Bee CH, Frostig RD (1999) Two directions of plasticity in the sensory-deprived adult cortex. Neuron 24:623-637. CrossRef Medline

Polley DB, Kvasnák E, Frostig RD (2004) Naturalistic experience transforms sensory maps in the adult cortex of caged animals. Nature 429:67-71. CrossRef Medline

Ramamurthy DL, Krubitzer LA (2016) The evolution of whisker-mediated somatosensation in mammals: sensory processing in barrelless S1 cortex of a marsupial, Monodelphis domestica. J Comp Neurol 524:3587-3613. CrossRef Medline

Rauschecker JP (1996) Substitution of visual by auditory inputs in the cat's anterior ectosylvian cortex. Prog Brain Res 112:313-323. CrossRef Medline
Rauschecker JP, Kniepert U (1994) Auditory localization behaviour in visually deprived cats. Eur J Neurosci 6:149-160. CrossRef Medline

Rauschecker JP, Korte M (1993) Auditory compensation for early blindness in cat cerebral cortex. J Neurosci 13:4538-4548. Medline

Rauschecker JP, Tian B, Korte M, Egert U (1992) Crossmodal changes in the somatosensory vibrissa/barrel system of visually deprived animals. Proc Natl Acad Sci U S A 89:5063-5067. CrossRef Medline

Renier L, De Volder AG, Rauschecker JP (2014) Cortical plasticity and preserved function in early blindness. Neurosci Biobehav Rev 41:53-63. CrossRef Medline

Ricciardi E, Handjaras G, Pietrini P (2014) The blind brain: how (lack of) vision shapes the morphological and functional architecture of the human brain. Exp Biol Med (Maywood) 239:1414-1420. CrossRef Medline

Sadka RS, Wollberg Z (2004) Response properties of auditory activated cells in the occipital cortex of the blind mole rat: an electrophysiological study. J Comp Physiol A Neuroethol Sens Neural Behav Physiol Neuroethol Sens Neural Behav Physiol 190:403-413. CrossRef Medline

Self MW, Lorteije JA, Vangeneugden J, van Beest EH, Grigore ME, Levelt CN, Heimel JA, Roelfsema PR (2014) Orientation-tuned surround suppression in mouse visual cortex. J Neurosci 34:9290-9304. CrossRef Medline

Sterr A, Müller MM, Elbert T, Rockstroh B, Pantev C, Taub E (1998a) Perceptual correlates of changes in cortical representation of fingers in blind multifinger braille readers. J Neurosci 18:4417-4423. CrossRef Medline

Sterr A, Müller MM, Elbert T, Rockstroh B, Pantev C, Taub E (1998b) Changed perceptions in braille readers. Nature 391:134-135. CrossRef Medline

Sterr A, Green L, Elbert T (2003) Blind braille readers mislocate tactile stimuli. Biol Psychol 63:117-127. CrossRef Medline

Taylor JS, Guillery RW (1994) Early development of the optic chiasm in the gray short-tailed opossum, Monodelphis domestica. J Comp Neurol 350: 109-121. CrossRef Medline

Toldi J, Farkas T, Völgyi B (1994) Neonatal enucleation induces crossmodal changes in the barrel cortex of rat: a behavioural and electrophysiological study. Neurosci Lett 167:1-4. CrossRef Medline

Vinje WE, Gallant JL (2000) Sparse coding and decorrelation in primary visual cortex during natural vision. Science 287:1273-1276. CrossRef Medline

Wang Q, Webber RM, Stanley GB (2010) Thalamic synchrony and the adaptive gating of information flow to cortex. Nat Neurosci 13:15341541. CrossRef Medline

Welker E, Soriano E, Dörfl J, Van der Loos H (1989) Plasticity in the barrel cortex of the adult mouse: transient increase of GAD-immunoreactivity following sensory stimulation. Exp Brain Res 78:659-664. CrossRef Medline

Welker E, Rao SB, Dörfl J, Melzer P, van der Loos H (1992) Plasticity in the barrel cortex of the adult mouse: effects of chronic stimulation upon deoxyglucose uptake in the behaving animal. J Neurosci 12:153-170. CrossRef Medline

Wong M, Gnanakumaran V, Goldreich D (2011) Tactile spatial acuity enhancement in blindness: evidence for experience-dependent mechanisms. J Neurosci 31:7028-7037. CrossRef Medline

Zheng D, Purves D (1995) Effects of increased neural activity on brain growth. Proc Natl Acad Sci U S A 92:1802-1806. CrossRef Medline

Zheng JJ, Li SJ, Zhang XD, Miao WY, Zhang D, Yao H, Yu X (2014) Oxytocin mediates early experience-dependent cross-modal plasticity in the sensory cortices. Nat Neurosci 17:391-399. CrossRef 